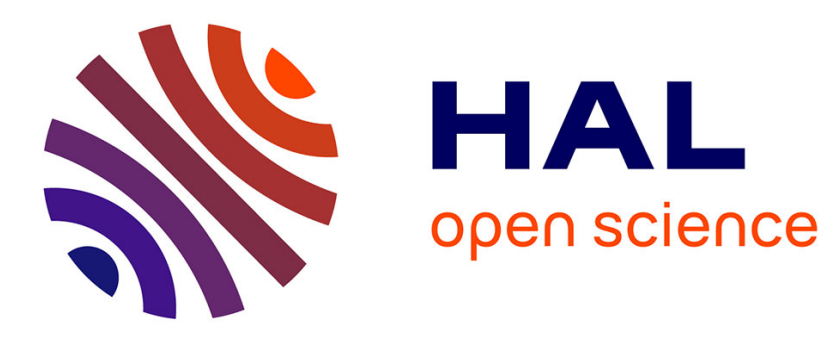

\title{
Reynolds-averaged navier-stokes simulations on NACA0012 and ONERA-M6 wing with the ONERA elsA solver
}

\author{
J. Mayeur, A. Dumont, D. Destarac, V. Gleize
}

\section{- To cite this version:}

J. Mayeur, A. Dumont, D. Destarac, V. Gleize. Reynolds-averaged navier-stokes simulations on NACA0012 and ONERA-M6 wing with the ONERA elsA solver. AIAA Journal, 2017, 54, pp.26712687. 10.2514/1.J054512 . hal-01426016

\section{HAL Id: hal-01426016 https://hal.science/hal-01426016}

Submitted on 3 Jan 2022

HAL is a multi-disciplinary open access archive for the deposit and dissemination of scientific research documents, whether they are published or not. The documents may come from teaching and research institutions in France or abroad, or from public or private research centers.
L'archive ouverte pluridisciplinaire HAL, est destinée au dépôt et à la diffusion de documents scientifiques de niveau recherche, publiés ou non, émanant des établissements d'enseignement et de recherche français ou étrangers, des laboratoires publics ou privés.

\section{(ㄷ)(1) $\$$}

Distributed under a Creative Commons Attribution - NonCommerciall 4.0 International 


\title{
Reynolds-Averaged Navier-Stokes Simulations on NACA0012 and ONERA-M6 Wing with the ONERA elsA Solver
}

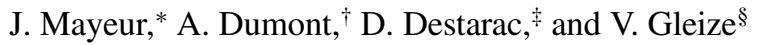 \\ ONERA-The French Aerospace Lab., F-92322 Chatillon, France
}

\begin{abstract}
Results of the elsA software package, the ONERA multipurpose tool for applied aerodynamics and multiphysics, are presented for a well-known NACA0012 configuration proposed by the turbulence modeling resource website of NASA Langley Research Center and on the ONERA-M6 wing. ONERA proposed new computer-aided design models for the turbulence modeling resources to make ONERA-M6 a reference test case. Results and solver performance are presented and discussed.
\end{abstract}

\section{Nomenclature}

$C_{D}=$ drag coefficient

$C_{D p}=$ pressure drag coefficient

$C_{D v}=$ friction drag coefficient

$C_{f}=$ skin friction coefficient

$C_{f, x}=x$ direction component of skin friction coefficient

$C_{L}=$ lift coefficient

$C_{M}=$ pitching moment coefficient

$C_{p}=$ wall pressure coefficient

$c=$ airfoil chord

$h \quad=$ mesh size

$M \quad=$ Mach number

$R e=$ Reynolds number

$u, U=x$ direction velocity component

$u^{+}=$dimensionless streamwise velocity

$v=y$ direction velocity component

$y^{+}=$dimensionless wall distance

$\alpha \quad=$ angle of attack

$\mu \quad=$ dynamic viscosity

$\mu_{t} \quad=$ turbulent viscosity

$\tilde{v}=$ turbulent variable of the Spalart-Allmaras model

\section{Introduction}

$\mathbf{S}$ INCE 1997, the elsA software package $[1,2]$ is the ONERA multipurpose tool for applied aerodynamics and multiphysics, which capitalizes on the innovative results of computational fluid dynamics (CFD) research over time. The elsA CFD simulation platform solves the compressible Navier-Stokes equations and deals with internal and external aerodynamics from the low-subsonic to the high-supersonic flow regime. A very wide range of aerospace applications is covered by elsA: aircraft, helicopters, tilt rotors, turbomachinery, counter-rotating open rotors, missiles, unmanned aerial vehicles, launchers, etc. The elsA software is also used for configurations outside the aerospace field, such as car turbochargers

Presented as Paper 2015-1745 at the 53rd AIAA Aerospace Sciences Meeting, Kissimmee, FL, 5-9 January 2015; received 29 May 2015; revision received 18 January 2016; accepted for publication 20 April 2016; published online 20 June 2016. Copyright (C) 2016 by the authors. Published by the American Institute of Aeronautics and Astronautics, Inc., with permission. Copies of this paper may be made for personal and internal use, on condition that the copier pay the per-copy fee to the Copyright Clearance Center (CCC). All requests for copying and permission to reprint should be submitted to CCC at www.copyright.com; employ the ISSN 0001-1452 (print) or 1533-385X (online) to initiate your request.

*Research Scientist, Computational Fluid Dynamics and Aeroacoustics Department; Julien.Mayeur@onera.fr.

'Research Scientist, Applied Computational Fluid Dynamics Department; Antoine.Dumont@onera.fr.

${ }^{\star}$ Research Scientist, Applied Computational Fluid Dynamics Department; Daniel.Destarac@onera.fr.

${ }^{\S}$ Research Scientist, Computational Fluid Dynamics and Aeroacoustics Department; Vincent.Gleize@onera.fr. and steam and wind turbines. The development and validation of the elsA software benefit by input from research partners and feedback from industry users [2]. In particular, elsA is used as a reliable CFD tool by Airbus for transport aircraft configurations, by the Safran group for turbomachinery flow simulations, and by Airbus Helicopter for helicopter applications.

A description of elsA and an illustration of the wide range of applications covered by elsA were shown by Cambier et al. [1]. In this previous work, the Reynolds-averaged Navier-Stokes (RANS) capabilities of the software have been assessed on largely used configurations from basic test cases provided by the NASA turbulence modeling resource (TMR) website [3] to transport aircraft, turbomachinery, and helicopter well-known applications often encountered in international community workshops. Nevertheless, the effort on the elsA validation has to be pursued and intensified, especially in collaboration with other major CFD software research centers, to build a reliable database allowing researchers to compare and highlight the most effective and accurate methods among those already implemented in each software. This can be helpful for the choice of the best new features to be implemented.

The first studied test case is the NACA0012 airfoil. A first campaign of computations was performed in a family zero grid with different turbulence models [Spalart-Allmaras, $k-\omega$ Menter shear stress transport (SST), explicit algebraic Reynolds stress modeling (EARSM) Hellsten] to analyze the turbulence model influence on the physics, then three families of grids with different relative grid densities at the trailing edge posted on the TMR website were used for analyzing numerical and performance aspects. These results are presented and compared with experimental data and CFL3D and FUN3D code solutions for the angle of attack equal to $10 \mathrm{deg}$.

The discussion and conclusions focus on two main aspects: the behavior of the solution (in physical and numerical points of view) and the software performance. The computations are systematically performed on different grid resolutions and the numerical convergence is carefully checked on each grid. Then, an assessment of the computing performances on the ONERA cluster in parallel mode is given.

The other test case is the ONERA-M6 wing (OM6). Indeed, in response to an expressed interest of the community to have a "simple" three-dimensional (3-D) test case to evaluate turbulent-flow solvers. Onera has worked on OM6 since 1977. Two cases for the OM6 wing are presented. The paper summarizes the status of OM6 validation studies, describes the wing geometry and the available experimental data, and justifies the choice of two inflow conditions. Finally, two CAD models (with blunt and sharp trailing edge) and grid generation, as well as preliminary results, are described and discussed, particularly, the effect of a sharp trailing edge on the pressure distribution.

\section{NACA0012 Airfoil}

The TMR website provides a central resource for turbulence model verification, which includes a precise definition of commonly used 

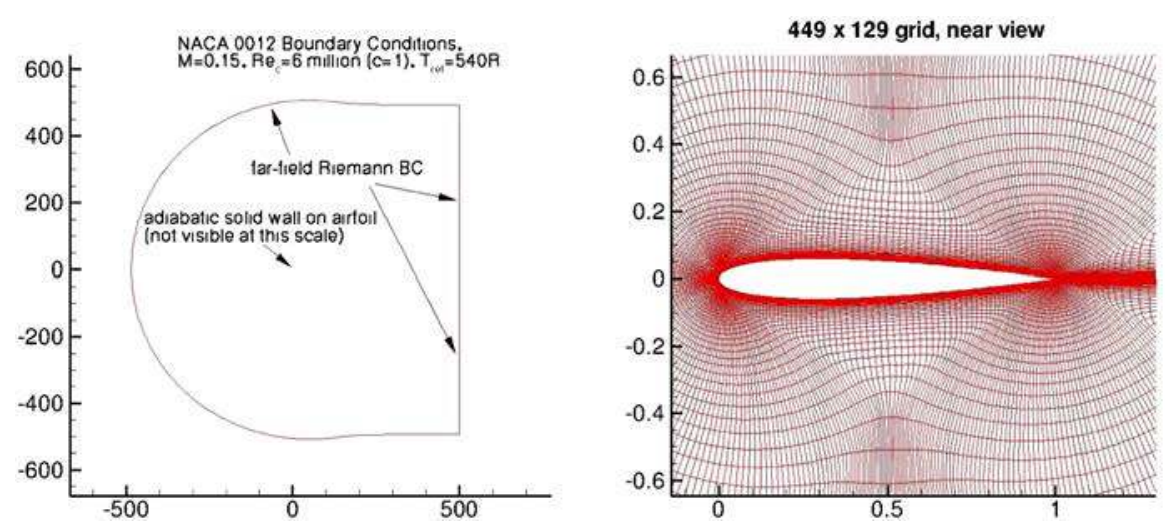

Fig. 1 NACA0012 airfoil computational domain and boundary conditions (family zero grid).

turbulence models and a set of test cases with supplied grids and sample results using different CFD codes. The sequence of progressively refined meshes that is provided for the test cases allows a verification of the correctness of implementation of the turbulence models and consistency of discretization.

The elsA RANS computations were performed using the secondorder upwind AUSM+(P) scheme [4] for space discretization, the backward Euler scheme with implicit lower-upper symmetric successive overrelaxation for time integration, and multigrid convergence acceleration. The AUSM+(P) is an upwind scheme based on a third-order MUSCL interpolation. The advantage of the AUSM+(P) scheme, which belongs to the family of AUSM schemes [5], is that it has no need of additional artificial dissipation and preserves the accuracy at low Mach number.

On graphics showing mesh convergence, parameter $h$ is defined as a function of the mesh size $N$ :

$$
h=\frac{1}{(N)^{1 / 3}}
$$

The NACA airfoils family includes shapes for aircraft wings developed by NACA. NASA Langley Research Center has worked on airfoils since 1920 and have performed wind-tunnel experiments since 1927. In 1933, 78 NACA airfoils were published. The NACA four-digit wing sections define the profile by 1) the first digit, describing the maximum camber as a percentage of the chord;2) the second digit, describing the distance of maximum camber from the airfoil leading edge in tens of percent of the chord; and 3) the last two digits, describing maximum thickness of the airfoil as a percent of the chord.

The NACA0012 airfoil is symmetrical; it has no camber. The "12" indicates that the airfoil has a $12 \%$ thickness-to-chord-length ratio. This case is designed primarily on the TMR website for numerical analysis of turbulence model simulations: convergence properties and effect of order and accuracy. The flow conditions are as follows: Mach number $M=0.15$ and Reynolds number based on length "1" of the grid $\operatorname{Re}=6 \times 10^{6}$. A freestream static temperature is $T_{\text {ref }}=540 \mathrm{R}$.

A mesh convergence on a family zero grid with five levels (Fig. 1) was performed with three turbulent models ( $k-\omega$ Menter SST, Spalart-Allmaras, and EARSM Hellsten). It has been verified that the implementation of the models in elsA is in full accordance with the description available on the TMR website, including the wall boundary conditions. In particular, the boundary condition on $\omega$ for
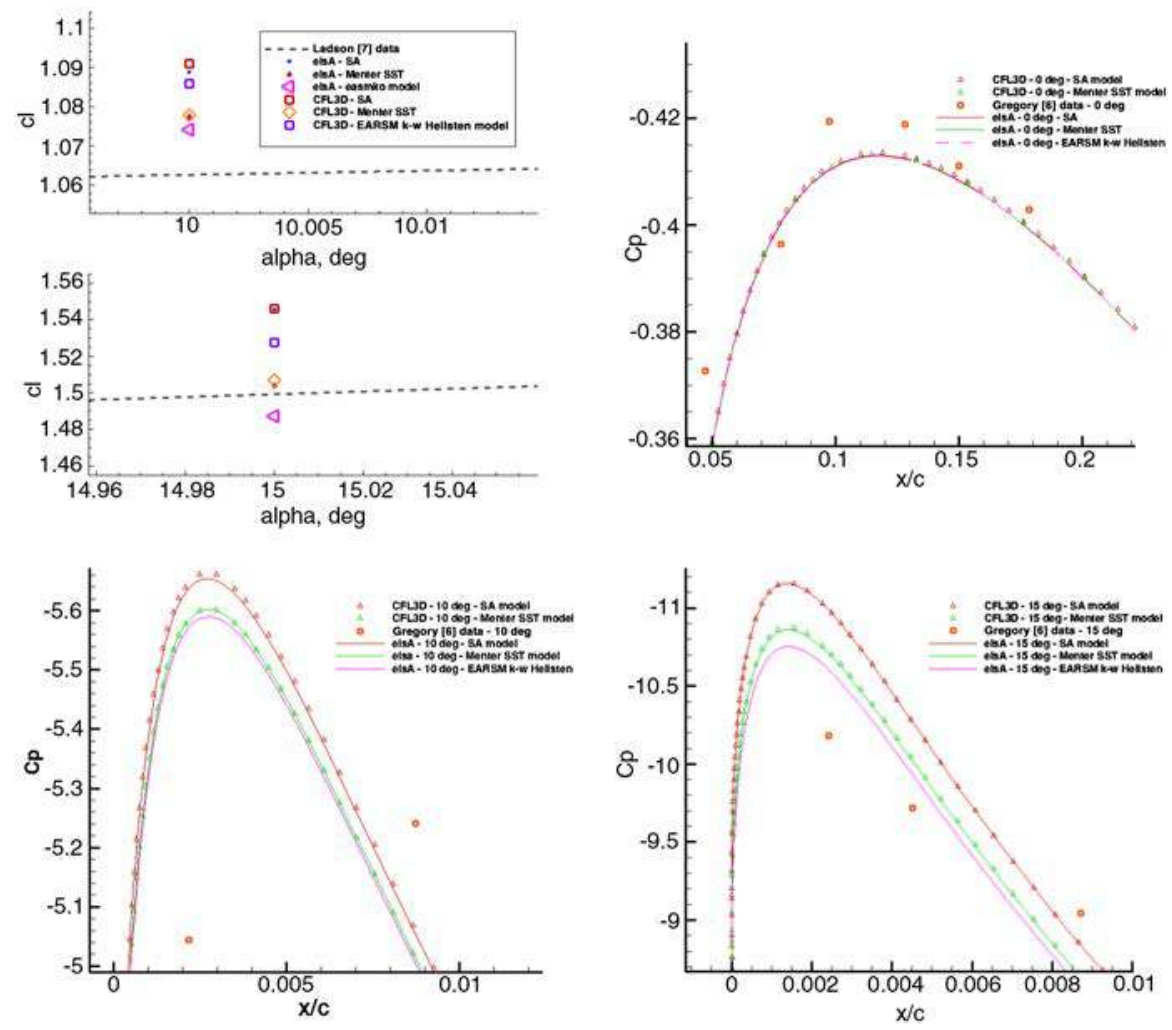

Fig. 2 Results on family zero finest grid. Close view of leading edge. 

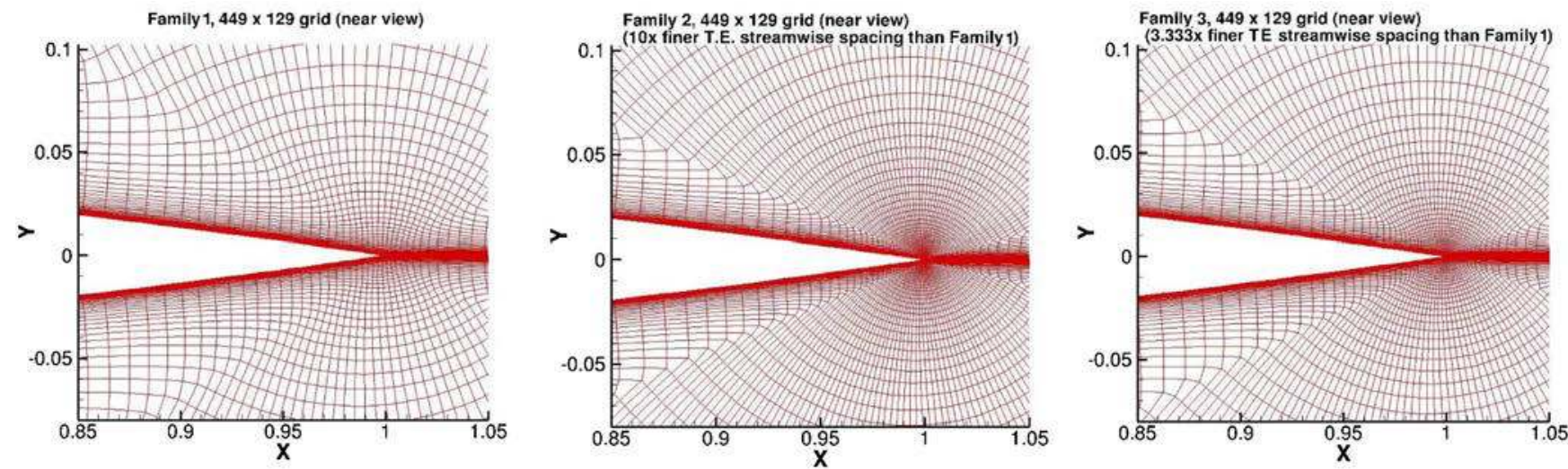

Fig. 3 NACA0012 airfoil, three families of grid (from TMR website).

the Menter SST model is exactly the same as the one used in the calculations presented on the website with the CFL3D code developed at NASA Langley.

Results given on the finest grid (Fig. 2) are compared with the CFL3D code, Gregory and O'Reilly [6] data, and Ladson data [7]. On a family zero grid, elsA and CFL3D results are almost indistinguishable (Fig. 2). The emphasis of the next analysis is now placed on numerics. For this purpose, new families of extremely fine grids have been created to explore the influence of different grid streamwise spacing at the trailing edge, which greatly influences the convergence properties. The computational domain and the boundary conditions are shown in Fig. 1.

Three families of grids are provided (Fig. 3) with seven levels of grid size. All have a far-field extent of approximately $500 \mathrm{c}$. Each family finest grid, $7169 \times 2049$, has a minimum cell size at the wall of $10^{-7}$, giving an approximate average $y^{+}$between 0.1 and 0.2 over the airfoil at the Reynolds number run. The leading-edge spacing along the airfoil in all families is the same: $0.0000125 c$. The difference between the families is in their trailing-edge streamwise spacing: family $1,0.000125 c$; family $2,0.0000125 c$; and family $3,0.0000375 c$

A mesh convergence was performed on the seven levels of grids for families 1 and 2, whereas family 3 was only computed in the finest level. The Spalart-Allmaras model has been used with an angle of attack of $10 \mathrm{deg}$. Convergence criterion was based on reaching five digits for the lift coefficient. All computations were performed without a point vortex boundary condition and with a second-order turbulence advection. The pitching moment was computed with respect to the $0.25 \mathrm{c}$. Performance of elsA has been summarized in Table 1, showing the CPU time by iteration and point for seven levels of grid size. It is influenced by the number of grids for the multigrid algorithm, the number of iterations in the coarse grid, the number of iterations for the turbulent system, and the number of processors used for computation. Table 1 gives an idea of the software scalability.

As shown in Fig. 4, families gave different results, particularly on lift, pitching moment, and the viscous part on the drag. The trailingedge streamwise spacing has an influence on lift and moment. The trailing-edge streamwise spacing on family 1 seems not to be sufficient. The trailing-edge streamwise spacing for family II is the smallest, and so this grid family should give the most accurate result. The next results have been computed on this family on the finest grid. Table 2 shows the relative difference between elsA and CFL3D on the finest grid for each aerodynamic coefficient. Pitching moments have a relative difference 100 times more important than those on lift or total drag. This coefficient has historically been difficult to accurately predict with CFD. Large differences in computed results would suggest the need for further investigation.

Figure 5 shows the pressure coefficients on the airfoil and the friction coefficient. The elsA software and CFL3D give consistent results compared with the experiment of Gregory and O'Reilly [6]. Differences appear by zooming in on the leading (Fig. 6, near $x=0$ ) and trailing edges (Fig. 7, near $x=1$ ). These differences are only visible in extreme zooms of the suction peak and very near the trailing edge. The elsA software has difficulties obtaining a smooth solution very near the trailing edge. It explains the plate convergence in the last lower right view of Fig. 4 (Family 1-7169x20489 grid); indeed it has been checked that residuals are the most high in this zone.

Figure 8 shows eddy viscosity and streamwise velocity components near the trailing edge. Results between codes are indistinguishable. Figure 9 shows eddy viscosity and velocity near the trailing edge from the upper side of the airfoil and the lower part of the airfoil. Results are interesting because the trailing edge is a sensitive point. Results are almost indistinguishable also. Away from the airfoil, in Fig. 10, velocity and eddy viscosity are more sensitive to the influence of the far-field condition. Very near the trailing edge, different behaviors of the pressure coefficient found by schemes elsA and CFL3D (Fig. 7) induce small differences in Fig. 11.

\section{A. Brief History of ONERA-M6}

\section{ONERA-M6 Wing}

The reputation of OM6 is largely due to Jameson [8-10]. The first wing test case addressed in [8] (1977) with the Flo22 full potential equation solver is OM6. Several flow conditions taken from [11] (1973 and 1975) are considered, including those have been preferred over the years by the majority of the CFD community $\left(M_{\infty}=0.84\right.$, $\alpha=3.06 \mathrm{deg}$ ). In 1979, Jameson and Caughey granted OM6 a fuselage to investigate fuselage effects on the flow past a wing [9], well aware that OM6 is not even a full wing, but is only "representative of the tip panel of a relatively simple wing of conventional high-speed section shape" [8].

In 1982, the editor of the Proceedings of IMA Conference on Numerical Methods in Aeronautical Fluid Dynamics appended a paper entitled "Transonic Airfoil Calculations Using the Euler

Table 1 Performance of elsA

\begin{tabular}{lccccccc}
\hline \hline Parameter & \multicolumn{7}{c}{ Value } \\
\cline { 2 - 8 } Grid level & M7 & M6 & M5 & M4 & M3 & M2 & M1 \\
\hline Number of points & $113 \times 33$ & $225 \times 65$ & $449 \times 129$ & $897 \times 257$ & $1793 \times 513$ & $3585 \times 1025$ & $7129 \times 2049$ \\
Number of iterations & 5350 & 10,754 & 11,600 & 22,931 & 52,563 & 62,099 & 72,319 \\
Number of multigrid grids/processors & $2 / 1$ & $2 / 8$ & $2 / 16$ & $2 / 32$ & $2 / 64$ & $3 / 128$ & $4 / 256$ \\
CPU time, s/iteration/points & $1.1 \times 10^{-5}$ & $1.3 \times 10^{-5}$ & $1.1 \times 10^{-5}$ & $1.6 \times 10^{-5}$ & $1.6 \times 10^{-5}$ & $2.4 \times 10^{-5}$ & $2.9 \times 10^{-5}$ \\
\hline \hline
\end{tabular}



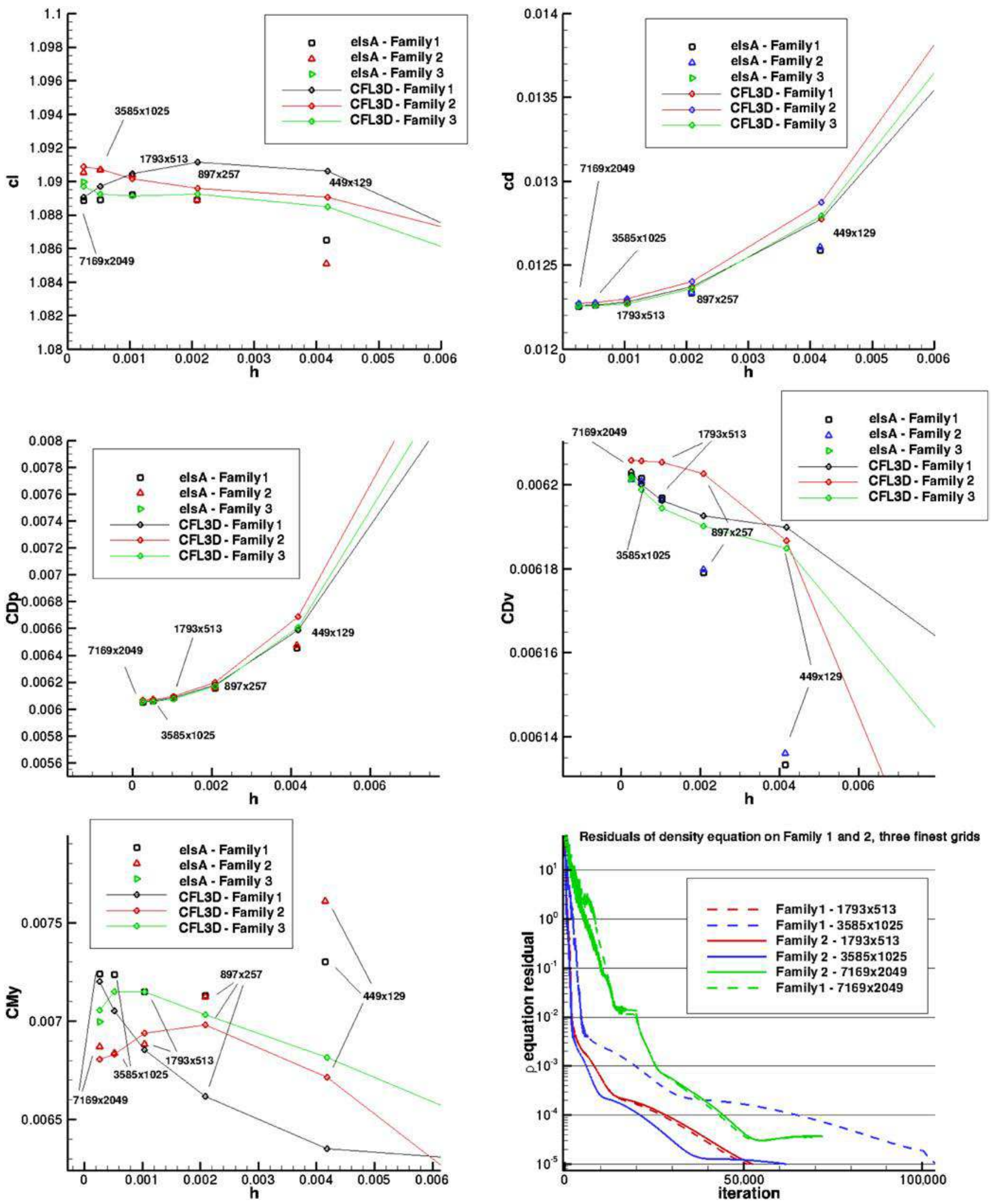

Fig. 4 Grid convergence and aerodynamic coefficients.

Table 2 Aerodynamic coefficients: comparison between elsA and CFL3D on finest family 2 grid

\begin{tabular}{lccccc}
\hline \hline Global coefficients & $C_{L}$ & $C_{D}$ & $C_{D p}$ & $C_{D v}$ & $C_{M y}$ \\
\hline elsA & 1.09054 & 0.01226 & 0.00606 & 0.00620 & 0.00687 \\
CFL3D & 1.09085 & 0.01227 & 0.00607 & 0.00620 & 0.00680 \\
Relative difference, \% & $2.1 \times 10^{-4}$ & $8.2 \times 10^{-4}$ & $1.6 \times 10^{-3}$ & 0.0 & $1.0 \times 10^{-2}$ \\
\hline \hline
\end{tabular}



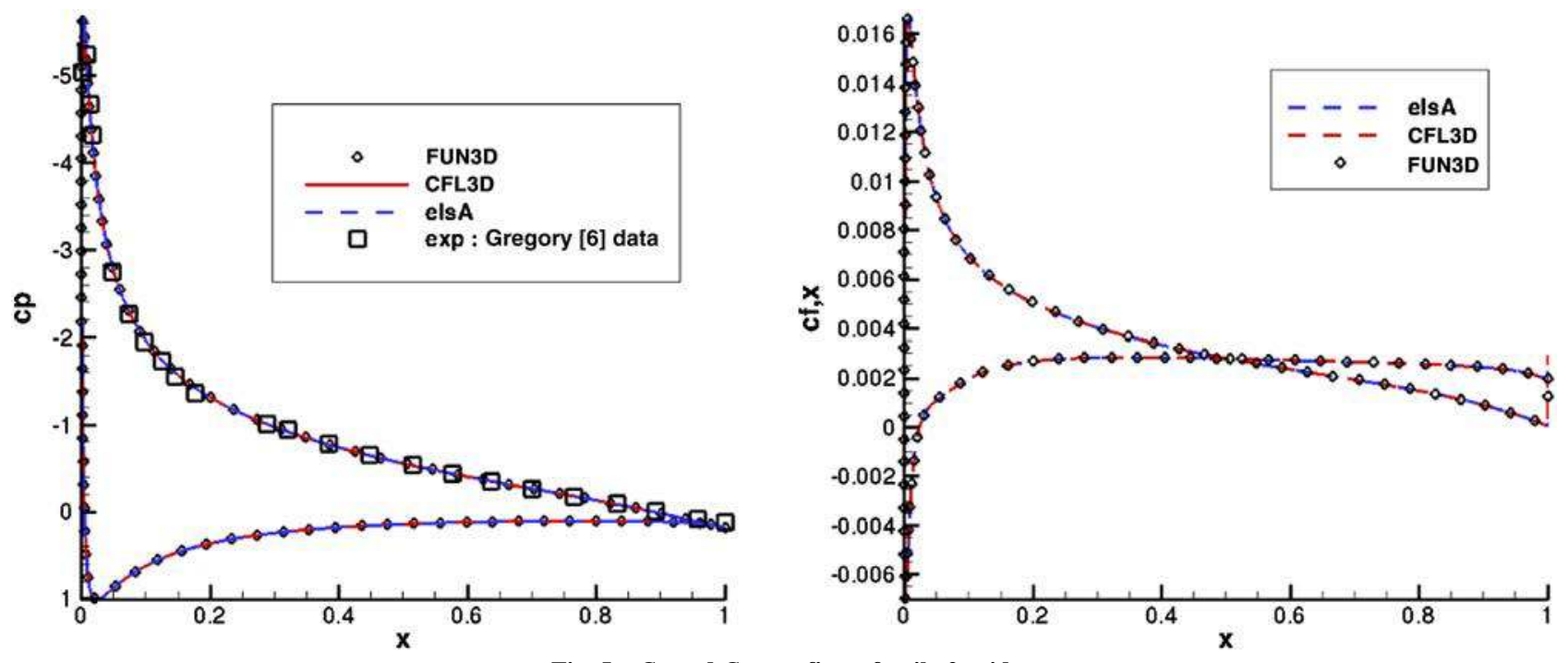

Fig. $5 C_{p}$ and $C_{f, x}$ on finest family 2 grid.

Equations" [10], Jameson's first published results of an Euler simulation past a wing, OM6 of course $\left(M_{\infty}=0.84, \alpha=3.06 \mathrm{deg}\right)$, with a comparison to a full potential simulation. In the late $1980 \mathrm{~s}$ and 1990s, the OM6 test case was used to validate (or invalidate)
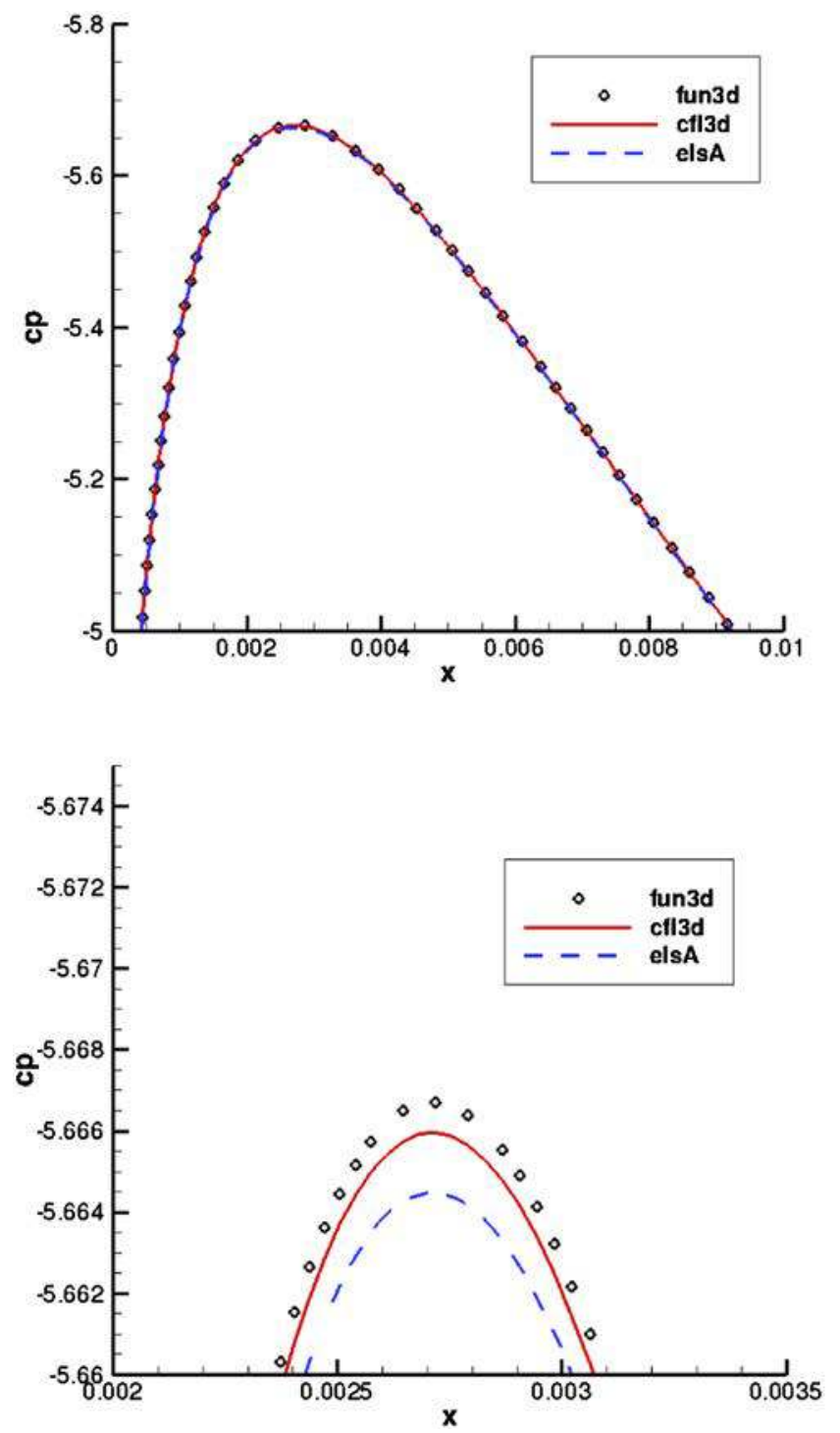

early 3-D separated viscous flow simulations. A second set of conditions, $M_{\infty}=0.84, \alpha=6.06 \mathrm{deg}, \quad R e_{c}=11.7 \times 10^{6}$, providing wide separation, was selected by several authors [12-15].
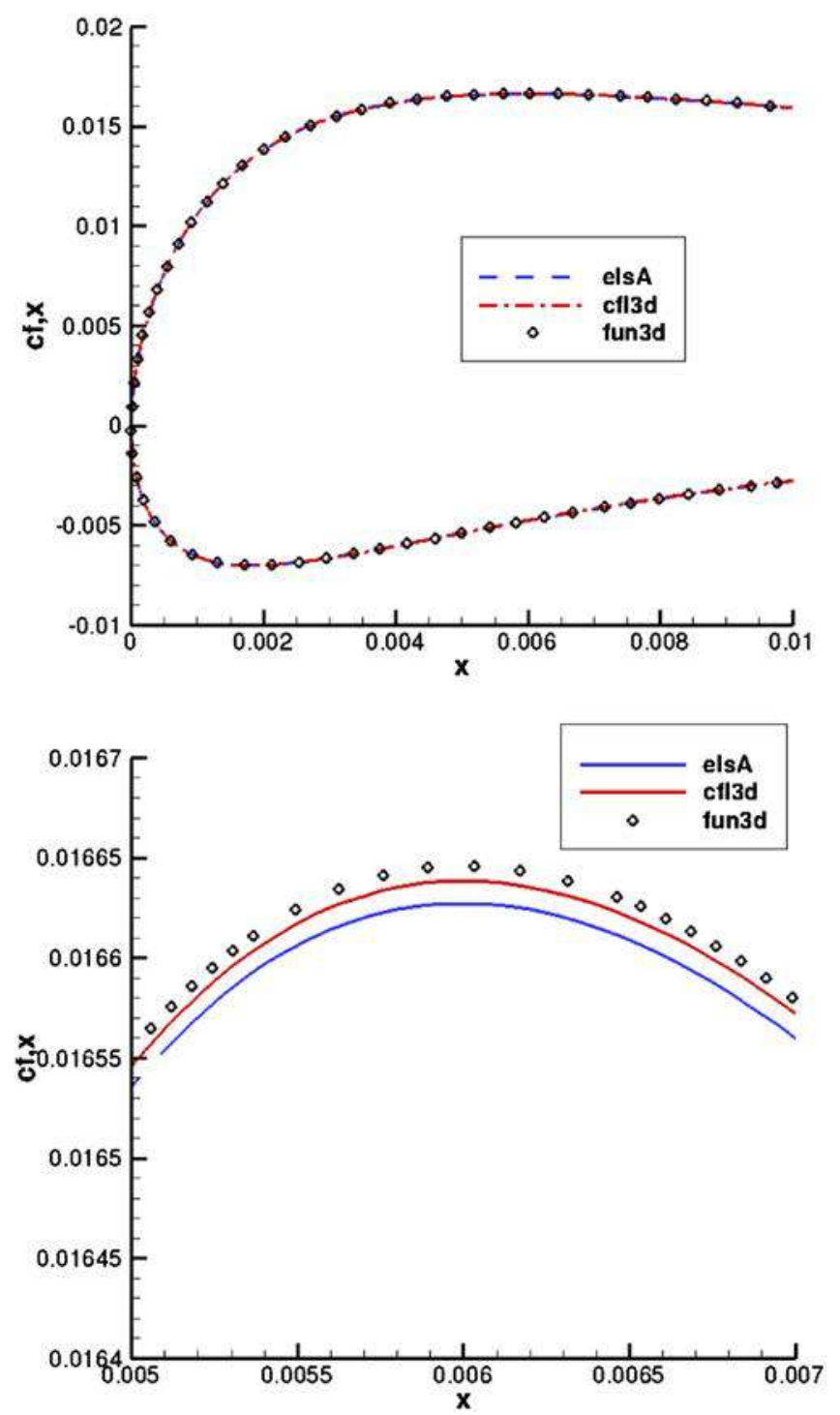

Fig. $6 C_{p}$ and $C_{f, x}$ on finest family 2 grid. Close view of leading edge and suction peak. 

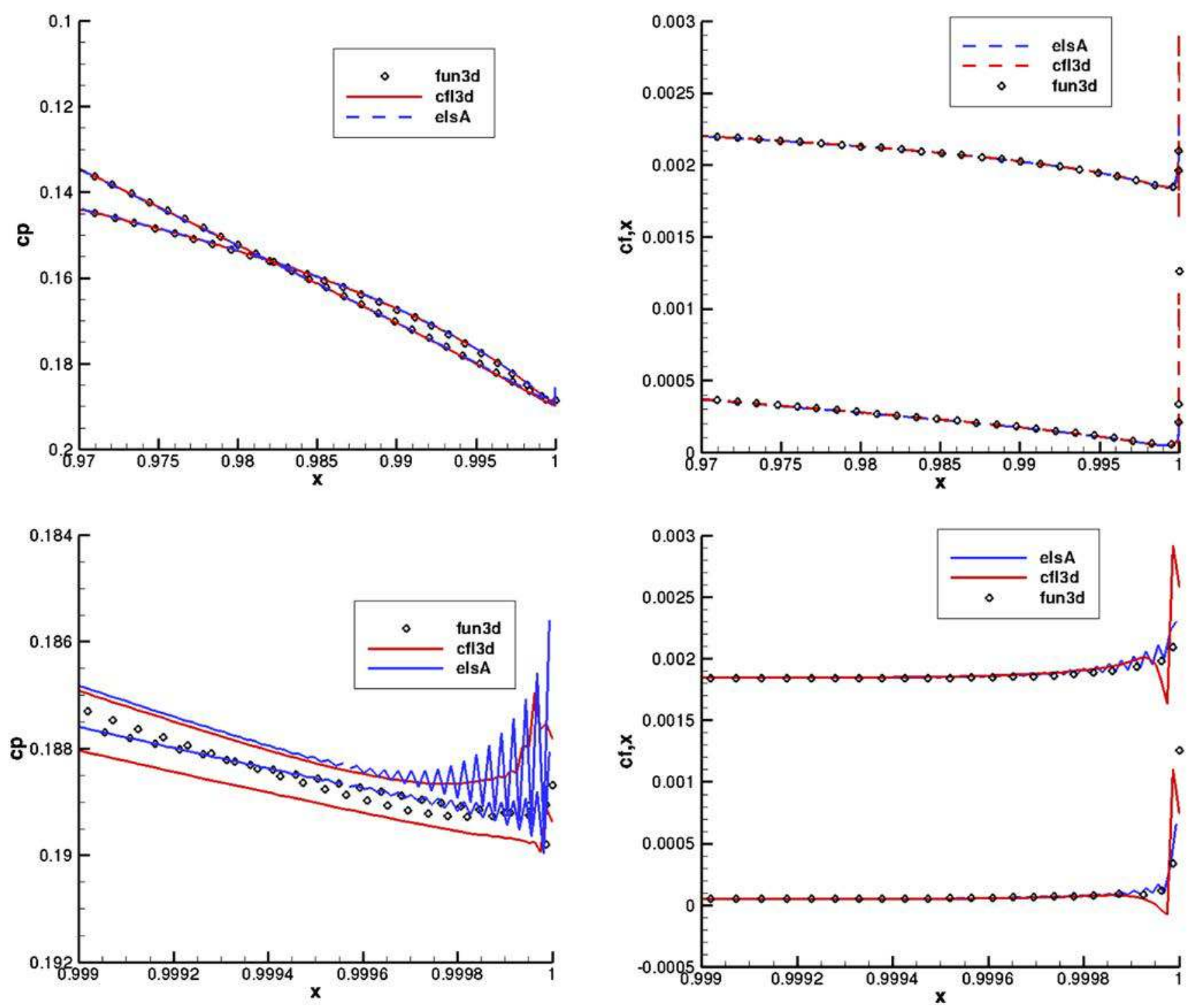

Fig. $7 C_{p}$ and $C_{f, x}$ on finest family 2 grid. Close view of trailing edge.
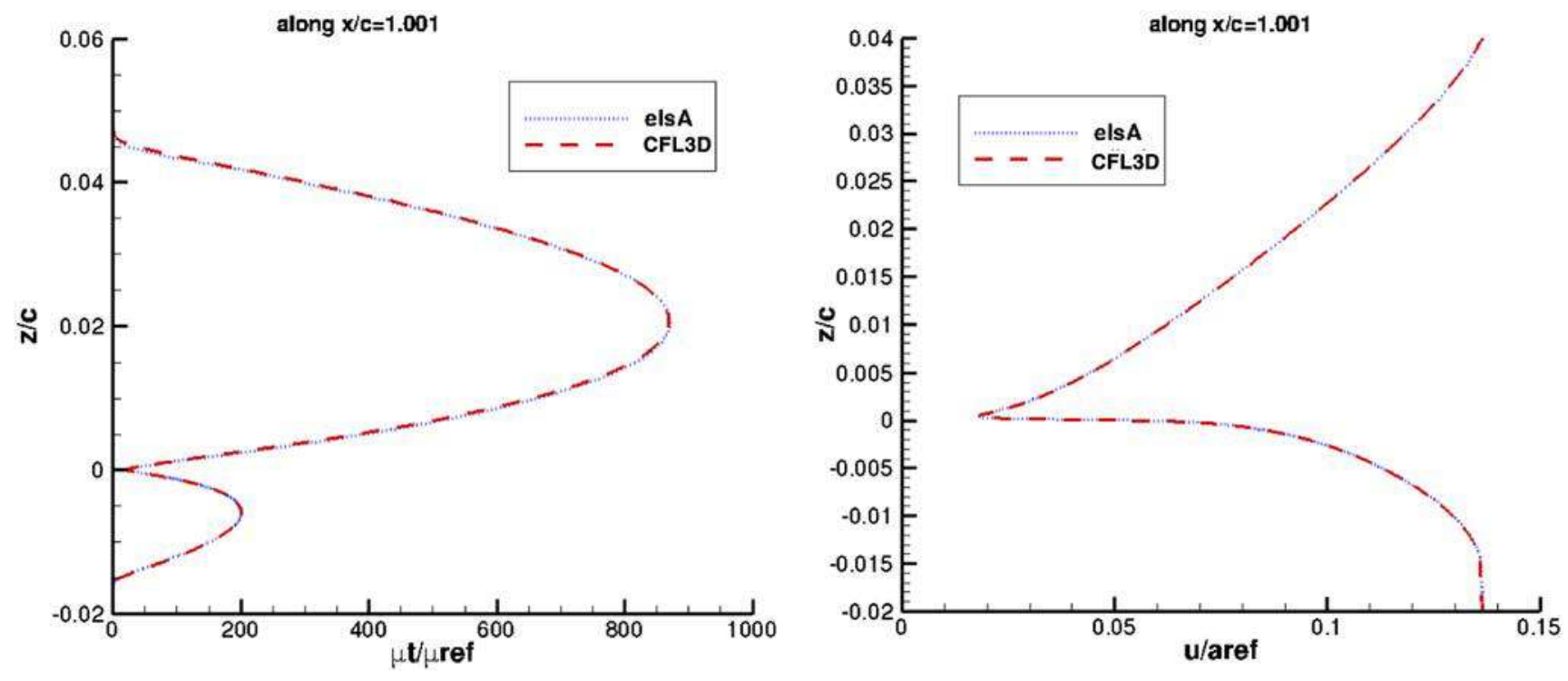

Fig. 8 Various profiles along $x / c=1.001$ line on finest family 2 grid. 

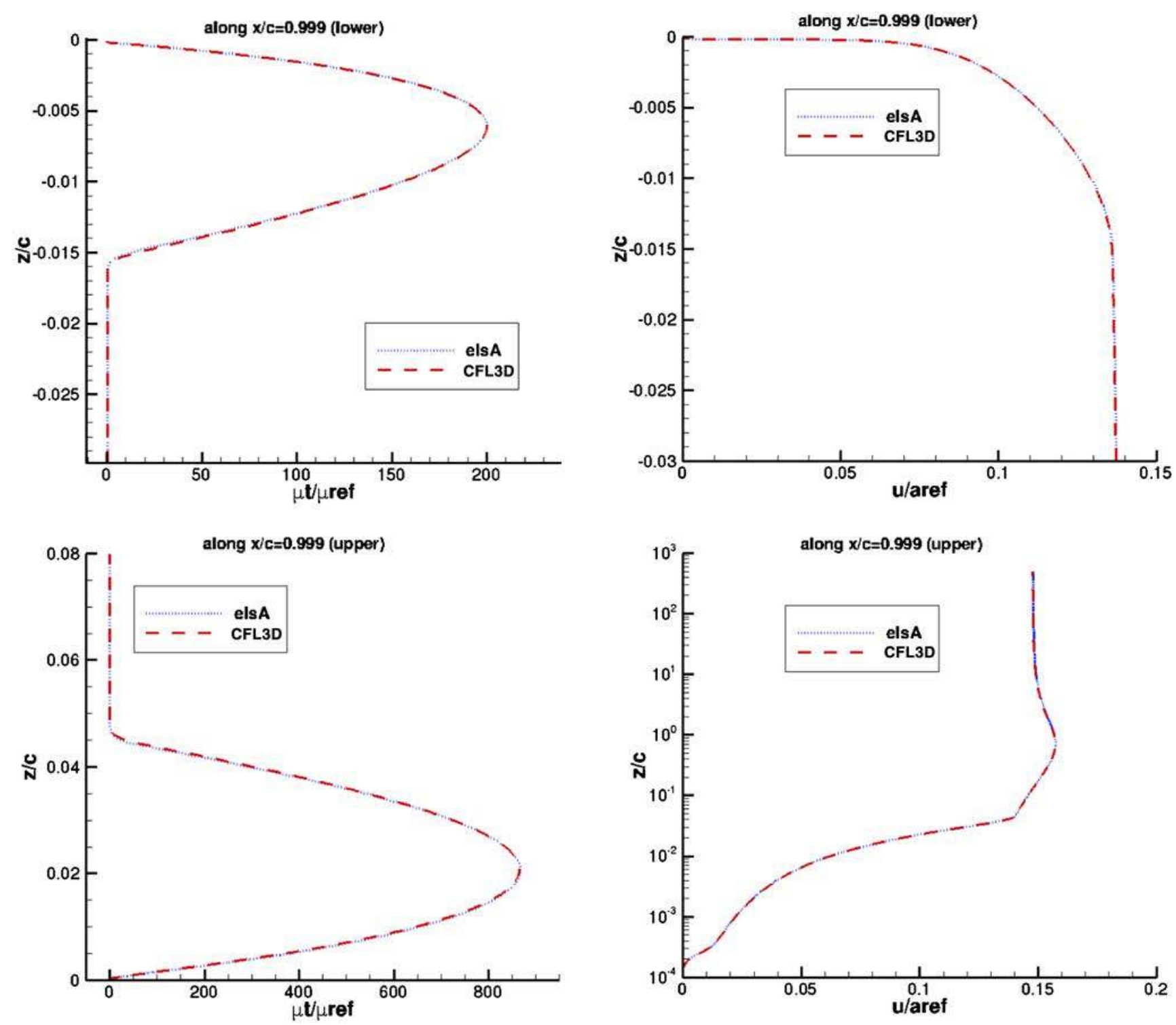

Fig. 9 Various profiles along $x / c=0.999$ line on finest family 2 grid.
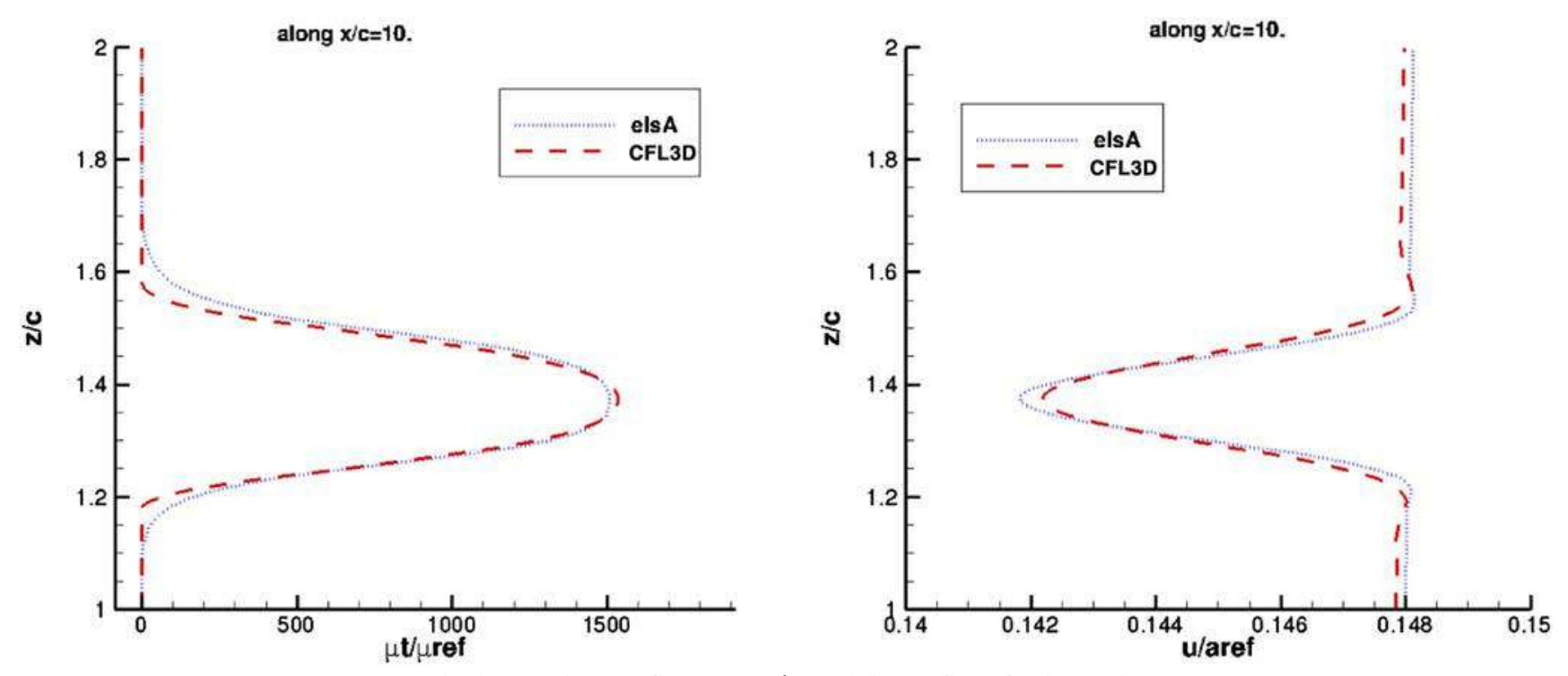

Fig. 10 Various profiles along $x / c=10$ line on finest family 2 grid. 

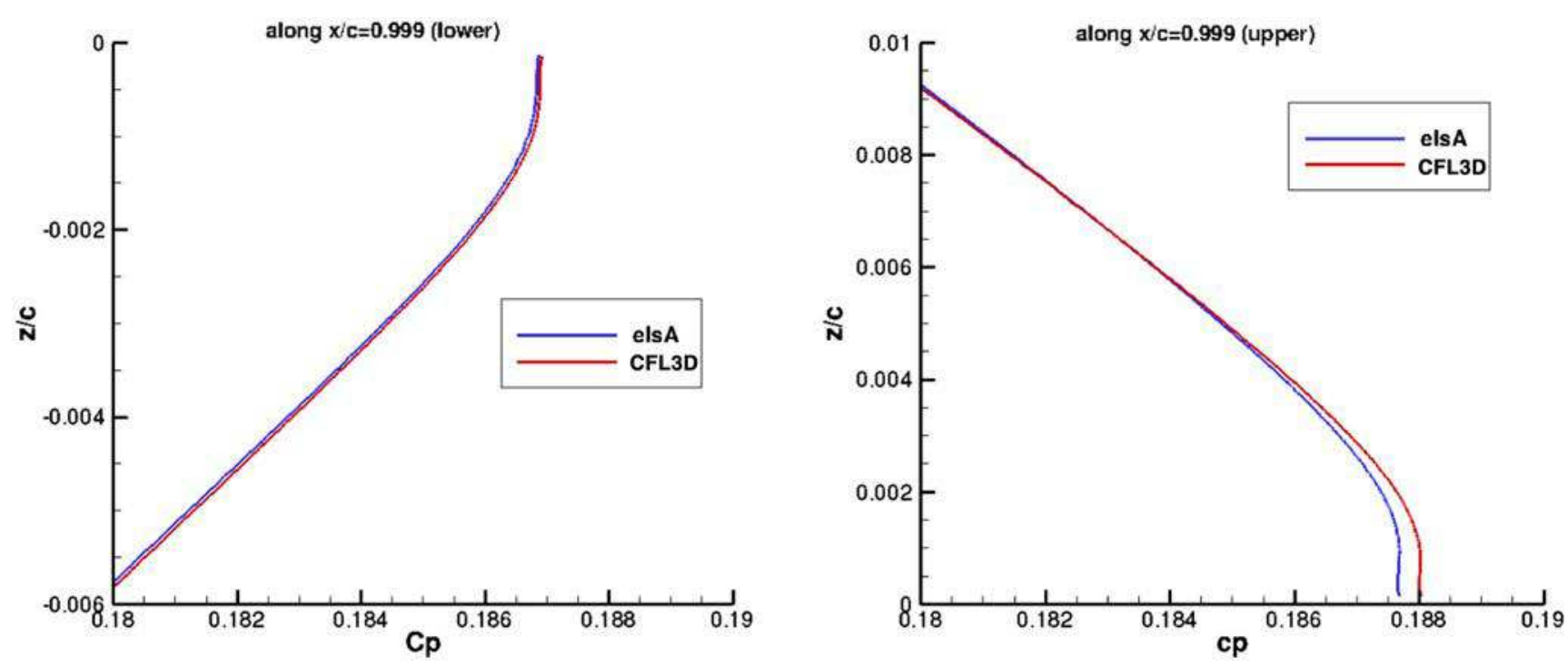

Fig. 11 Pressure coefficients profiles along $x / c=0.999$ lines on finest family 2 grid.

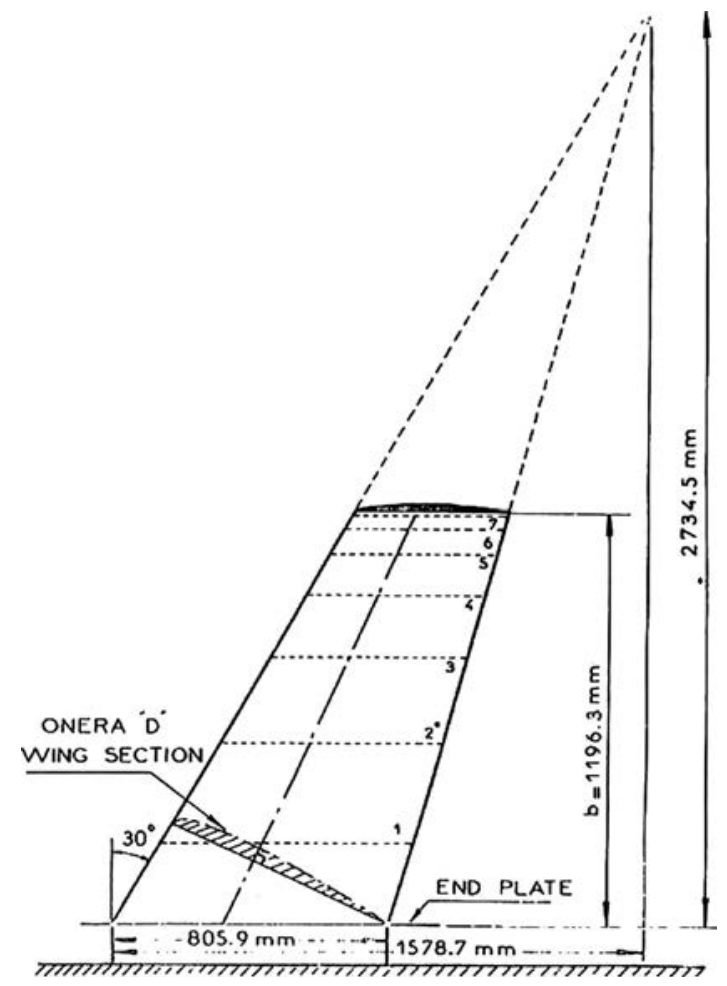

Fig. 12 Layout of the OM6 wing planform from [17].

Several years later, OM6 was still among the validation cases of the then-latest flow software, Flo3 $\mathrm{xx}$, designed for simulations in arbitrary meshes [16] (2005). In 2011, it appears in a paper dedicated to an approximate Riemann solver [17].

\section{B. ONERA-M6 AGARD Test Case (1979)}

In 1979, NATO's Advisory Group for Aerospace Research and Development (AGARD) issued Report AR-138 entitled "Experimental Data Base for Computer Program Assessment." The two most enduring test cases of this rich and accurate compendium are the RAE2822 airfoil and the OM6 wing.

Schmitt and Charpin described the OM6 test case [17]. OM6 borrows the shape of the outer third of the ONERA calibration model M5 wing. The generating airfoil is of the peaky type. The wing planform is defined by the layout reproduced here in Fig. 12. The wing is produced through conical generation from a unique

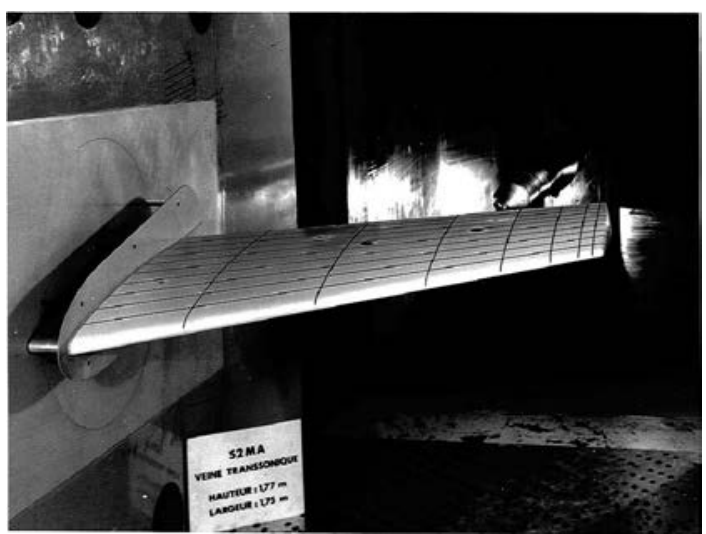

Fig. 13 ONERA-M6 wing model in the ONERA-S2MA wind tunnel (from [17]).

symmetrical airfoil: all sections are homothetic. The upper surface wing root section is given in 72 point $(x, z)$ nondimensional coordinates. Note that the data are those of a longitudinal section, not of the generating airfoil (ONERA-D) in the usual aerodynamic sense. The trailing edge has a $0.14104 \%$ base thickness. The form of the wing tip is "truncation parallel to the wing root and addition of a half body of revolution." The conventional mean aerodynamic chord for the Reynolds number expression and reference area for aerodynamic coefficients are, respectively, $c=0.64607 \mathrm{~m}$ and $A_{\text {ref }}=0.7532 \mathrm{~m}^{2}$.

Experimental data gathered in [17] were produced in the ONERA pressurized S2MA wind tunnel (Fig. 13). The height and width of the test section were 1.770 and $1.750 \mathrm{~m}$ for a model of (semi)span $1.1963 \mathrm{~m}$. The model was assumed to be rigid. Transition was free. The setting included a boundary-layer diverter (half-model).

Data consist exclusively of pressure coefficient distributions: no lift, drag, or moment coefficients, no flow visualizations, and no unsteady data. Pressure distributions are given in seven spanwise sections for 30 aerodynamic conditions, ranging from $M_{\infty} \approx 0.70$ and $\alpha=0 \mathrm{deg}$ to $M_{\infty} \approx 0.93$ and $\alpha=6 \mathrm{deg}, 11.63$ million $<$ $\operatorname{Re}<11.83$ million.

\section{ONERA-M6 Wing Test Case Proposal}

The purpose of the present document is to propose a nonambiguous definition of the OM6 wing test case and to reduce the data to what is strictly necessary for CFD. 
Table 3 ONERA-M6 wing section nondimensional coordinates

\begin{tabular}{lccc}
\hline \hline$x / c$ & $z / c$ & $x / c$ & $z / c$ \\
\hline 0.0000000 & 0.0000000 & 0.3761446 & 0.0489296 \\
$\mathbf{0 . 0 0 0 0 1 6 5}$ & 0.0006914 & 0.4018567 & 0.0488202 \\
0.0000696 & 0.0014416 & $\mathbf{0 . 4 2 7 4 2 2 3}$ & 0.0484833 \\
0.0001675 & 0.0022554 & 0.4528441 & 0.0479351 \\
0.0003232 & 0.0031382 & 0.4781197 & 0.0471661 \\
0.0005508 & 0.0040959 & 0.5032514 & 0.0461903 \\
0.0008657 & 0.0051343 & 0.5282426 & 0.0450209 \\
0.0012868 & 0.0062598 & 0.5530937 & 0.0436741 \\
0.0018364 & 0.0074784 & 0.5778043 & 0.0421684 \\
0.0025441 & 0.0087958 & 0.6023757 & 0.0405241 \\
0.0034428 & 0.0102163 & 0.6268104 & 0.0387613 \\
0.0045704 & 0.0117419 & 0.6511093 & 0.0368990 \\
0.0059751 & 0.0133708 & 0.6752726 & 0.0349542 \\
0.0077112 & 0.0150951 & 0.6993027 & 0.0329402 \\
0.0098413 & 0.0168984 & 0.7231995 & 0.0308662 \\
0.0124479 & 0.0187537 & 0.7469658 & 0.0287365 \\
0.0156171 & 0.0206220 & 0.7705998 & 0.0265505 \\
0.0194609 & 0.0224545 & 0.7941055 & 0.0243027 \\
0.0241067 & 0.0242004 & 0.8174828 & 0.0219842 \\
0.0297008 & 0.0258245 & 0.8407324 & 0.0195838 \\
0.0364261 & 0.0273317 & 0.8638564 & 0.0170915 \\
0.0444852 & 0.0287912 & 0.8868235 & 0.0145051 \\
0.0541248 & 0.0303278 & 0.9061905 & 0.0122389 \\
0.0656303 & 0.0320138 & 0.9225336 & 0.0102727 \\
0.0793366 & 0.0338372 & 0.9363346 & 0.0085827 \\
0.0956354 & 0.0357742 & 0.9479946 & 0.0071423 \\
0.1149796 & 0.0377923 & 0.9578511 & 0.0059224 \\
0.1378963 & 0.0398522 & $\mathbf{0 . 9 6 6 1 8 6 0}$ & 0.0048907 \\
0.1649976 & 0.0419089 & $\mathbf{0 . 9 7 3 2 3 6 1}$ & 0.0040180 \\
0.1919327 & 0.0436214 & $\mathbf{0 . 9 7 9 2 0 2 0}$ & 0.0032796 \\
0.2187096 & 0.0450507 & $\mathbf{0 . 9 8 4 2 5 0 8}$ & 0.0026547 \\
0.2453310 & 0.0462358 & $\mathbf{0 . 9 8 8 5 2 5 2}$ & 0.0021257 \\
0.2717978 & 0.0471987 & $\mathbf{0 . 9 9 2 1 4 3 8}$ & 0.0016778 \\
0.2981113 & 0.0479494 & $\mathbf{0 . 9 9 5 2 0 8 0}$ & 0.0012985 \\
0.3242726 & 0.0484902 & $\mathbf{0 . 9 9 7 8 0 3 0}$ & 0.0009773 \\
0.3502830 & 0.0488183 & 1.0000000 & 0.0007052 \\
\hline \hline & & & \\
& & & \\
& & &
\end{tabular}

\section{A. Planform}

The planform is sketched in Fig. 12. Let us denote $A$ and $B$ as the root leading- and trailing-edge points, and $C$ as the apex of the prolonged trapezoidal planform. Following Fig. 12, one can adopt the following:

$$
\begin{aligned}
\left(X_{A}, Y_{A}\right) & =(0.0000,0.0000 \mathrm{~m}) \\
\left(X_{B}, Y_{B}\right) & =(0.8059,0.0000 \mathrm{~m}) \\
\left(X_{c}, Y_{c}\right) & =(1.5787,2.7345 \mathrm{~m})
\end{aligned}
$$

and cut the triangle at

$$
Y_{\mathrm{CUT}}=B=1.1969 \mathrm{~m}
$$

The consistency of the leading- and trailing-edge sweep angles printed in [12] with this definition is approximate. It has been decided to consider the angle values of [17] (30 and $15.8 \mathrm{deg}$ ) as approximations of (29.99899 and $15.78088 \mathrm{deg}$ ) and to validate the preceding metric data. The issue of the rounded tip will be addressed in a subsequent subsection.

\section{B. Wing Section, Generation of Wing Discrete Data}

The reduced coordinates of the wing section printed in [17] are not legible with certitude in the copies that D. Destarac consulted. However, they have been archived by NASA and are available at the following address: http://www.grc.nasa.gov/WWW/wind/valid/m6wing/airfoil. txt [retrieved 05 January 2015] (airfoil.txt). Plotting the section curvature leaves no doubt about their exactitude. They are gathered in Table 3 (upper half-section, nondimensional). The conical part of the wing can be entirely described by two sections, $Y=0$ and $Y=B$.

The written description of the wing tip shape in [17], truncation parallel to wing root and addition of a half-body of revolution, does not specify the axis of the closing rotation. A unique $x$-aligned axis is unlikely because it would produce an unpleasant "shoulder" near the leading edge. It has been chosen here to define a swept wing tip as illustrated in Fig. 14. Section rotation is carried out in vertical planes oriented along the local sweep angle.

Wing discrete data are available in a POINT ASCII tecplot file containing two zones: the trapeze zone consisting of two sections of 143 points (a half-section being defined in Table 3 by 72 points), and the tip zone consisting of 72 sections of 181 points ( $180 \mathrm{deg}, 1 \mathrm{deg}$ per interval; see again Fig. 14). The OM6 wing thus described is illustrated in Fig. 15. A FORTRAN routine producing these data from the section data is provided along with the tecplot file.

\section{Aerodynamic Conditions}

The 30 sets of aerodynamic conditions of [17] are listed in Table 4. Since 1977 [8], tradition has established $M_{\infty}=0.84$ instead of $M_{\infty}=0.8395$ for test number 2308, and since 1989 [13], $M_{\infty}=$ 0.84 has been used instead of $M_{\infty}=0.8372$ for test number 2565 , although the difference would be very small.

\section{Pressure Coefficient Distributions}

The AGARD document contains chordwise pressure distributions in seven spanwise sections for all 30 aerodynamic conditions. Section locations are given in Table 5. ASCII files exactly reproducing the pages of [18] given the pressure coefficient distribution are available, as well as an ASCII tecplot file containing the same data.

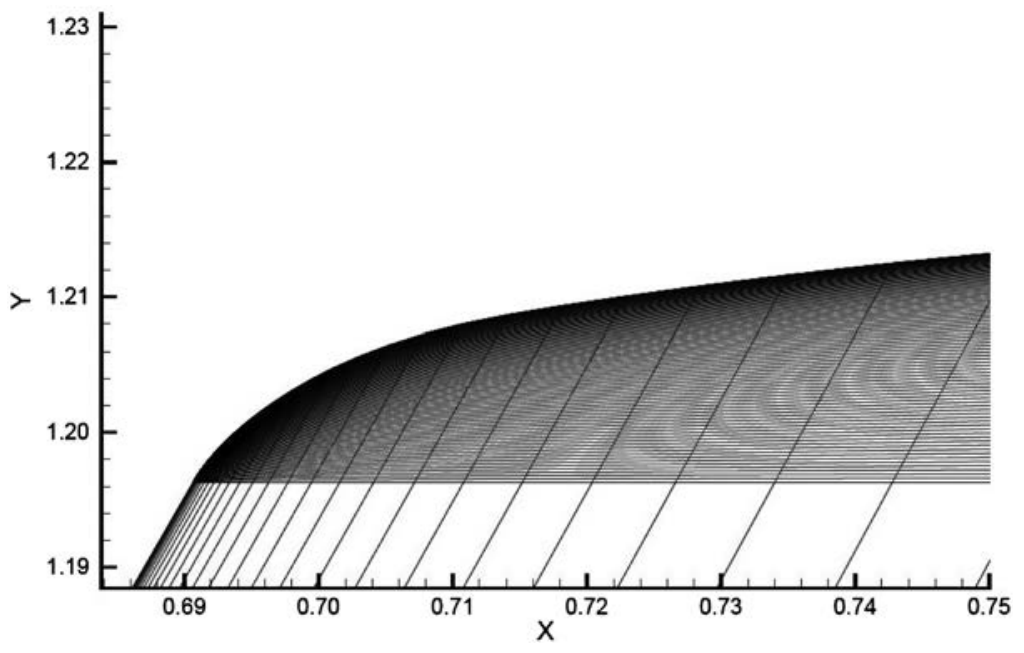

Fig. 14 Swept wing tip definition (leading-edge area). 


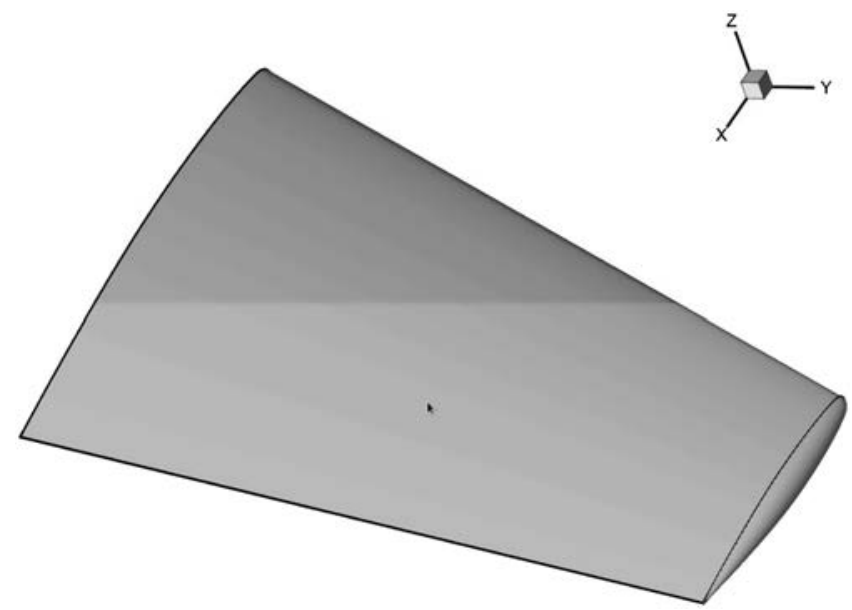

Fig. 15 ONERA-M6 wing described by two tecplot zones.

\section{E. Proposed Aerodynamic Conditions}

To avoid inefficient scatter of the CFD contributions, it is proposed to limit the number of aerodynamic conditions to two: 1) the well-known attached case, $M_{\infty}=0.84, \alpha=3.06 \mathrm{deg}, R e_{c}=$ $11.72 \times 10^{6}$, test 2308; and 2) a separated flow case, $M_{\infty}=0.84$, $\alpha=6.06 \mathrm{deg}, R e_{c}=11.71 \times 10^{6}$, test 2565 .

\section{F. Conclusion: Justification of the Present Proposal}

The present work is an attempt at giving a second wind to the wellknown OM6 wing test case for CFD validation. This required redocumenting it with as little ambiguity and uncertainty as possible, given the fact that no member of the original OM6 team can be contacted any longer.

The OM6 test case is by no means a competitor to more recent test cases (e.g., the common research model (CRM) of Vassberg et. al.

Table 4 ONERA-M6 test case aerodynamic conditions [17]

\begin{tabular}{lccc}
\hline \hline Test number & $M_{\text {inf }}$ & $\alpha$ & $R e$ \\
\hline 2309 & 0.6998 & 0.04 & 11.74 \\
2551 & 0.6977 & 0.06 & 11.67 \\
2310 & 0.7003 & 1.08 & 11.74 \\
2311 & 0.7001 & 2.06 & 11.74 \\
2312 & 0.6990 & 3.06 & 11.74 \\
2313 & 0.7009 & 4.08 & 11.77 \\
2541 & 0.7019 & 5.06 & 11.66 \\
2542 & 0.6971 & 6.09 & 11.63 \\
2305 & 0.8399 & 0.04 & 11.72 \\
2396 & 0.8371 & 0.03 & 11.69 \\
2306 & 0.8398 & 1.07 & 11.71 \\
2307 & 0.8386 & 2.06 & 11.72 \\
2308 & $\mathbf{0 . 8 4 0 0}[0.8395]$ & 3.06 & 11.72 \\
2563 & 0.8359 & 4.08 & 11.81 \\
2564 & 0.8447 & 5.06 & 11.78 \\
2565 & $\mathbf{0 . 8 4 0 0}[0.8372]$ & 6.06 & 11.71 \\
2300 & 0.8840 & 0.03 & 11.71 \\
2301 & 0.8833 & 1.08 & 11.77 \\
2302 & 0.8803 & 2.05 & 11.78 \\
2304 & 0.8809 & 3.06 & 11.77 \\
2591 & 0.8831 & 4.07 & 11.78 \\
2592 & 0.8808 & 5.07 & 11.78 \\
2593 & 0.8868 & 6.07 & 11.83 \\
2296 & 0.9207 & 0.03 & 11.78 \\
2297 & 0.9208 & 1.07 & 11.79 \\
2298 & 0.9180 & 2.05 & 11.76 \\
2299 & 0.9190 & 3.07 & 11.77 \\
2583 & 0.9262 & 4.08 & 11.73 \\
2584 & 0.9181 & 5.06 & 11.69 \\
2585 & 0.9298 & 6.07 & 11.71 \\
\hline \hline & & & \\
& & & \\
& & & \\
& & &
\end{tabular}

[18]). Indeed, we aim at an exactly opposite niche. The CRM is a rich and complex test case. OM6 is a "pocket" test case.

The OM6 test case contains several aerodynamic conditions involving massive three-dimensional separation (high Mach numbers, high angles of attack). In the 1970s, when it was published, such flows were well out of range of CFD. So the attached flow case, $M_{\infty}=0.84, \alpha=3.06 \mathrm{deg}, R e_{c}=11.72 \times 10^{6}$, remains the most popular. We propose here a second case with separated flow, computed in the past by a few authors [13]. Aerodynamic conditions are $M_{\infty}=0.84, \alpha=6.06 \mathrm{deg}, R e_{c}=11.71 \times 10^{6}$. One of the justifications of the present proposal is that a second wind for the OM6 test case could thus produce a delayed return on ONERA's investment, which would be a benefit for the CFD community.

\section{ONERA-M6 Wing Preliminary Computations}

In this section, the 3-D test case proposed by ONERA for the NASA solver technology technical discussion group will be presented. It consists of the computation of the well-known OM6 wing for an attached case. Results are compared with the experimental data extracted from an AGARD work group in the 1970s [18]. The experiment was done in the ONERA wind tunnel S2MA of Modane-Avrieux. The CAD model generation is introduced. Two types of meshes are presented; they share the same topology but differ from their number of points. Computation results on the two meshes are presented and compared with the experimental data.

\section{A. CAD Model with a Blunt Trailing Edge}

A CAD model based on the initial discrete data described in Sec. III was built. CATIA, Dassault System software, was used to generate the CAD model. The strategy adopted during the surface generation was to keep as many points possible from the initial discrete model and take some freedom concerning points that were responsible for oscillation in the shape to generate at the end a CAD model as smooth as possible.

At the start of the root profile generation, a problem appeared and led to the conclusion that no B spline computed in CATIA and passing by all 72 points defining the half-section was able to represent smoothly the shape of the profile. Point no. 2 (in order of appearance in Table 3) was removed from the B-spline definition, which ensures to set properly the radius (set at $0.01255 \mathrm{~m}$ ) and a vertical tangency constraint on the leading-edge point. It also turned out that point no. 39 was responsible for a curvature variation in the B-spline model, which was not intended in the original design, and so it has been removed. The most important reduction of passing points appears in the trailing-edge region, where the shape is nearly linear. Points 64 71 were removed because they induced a very wavy evolution of the curvature with changes of sign. Removed points are in bold font in Table 3. From there, a smooth profile, passing by all remaining points could be set. The same strategy was used to build the B-spline model representing the tip profile, the only difference being the value at which the leading-edge radius was set. This value was obtained by multiplying the radius of the root profile by the ratio of tip to root chord. From there, a surface defined by multisection lofting was created, using as guides curves, two straight lines joining the leading

Table 5 Spanwise locations of chordwise pressure coefficient distribution

\begin{tabular}{lc}
\hline \hline Section number & $\eta=Y / b$ \\
\hline 1 & 0.20 \\
2 & 0.44 \\
3 & 0.65 \\
4 & 0.80 \\
5 & 0.90 \\
6 & 0.96 \\
7 & 0.99 \\
\hline \hline
\end{tabular}




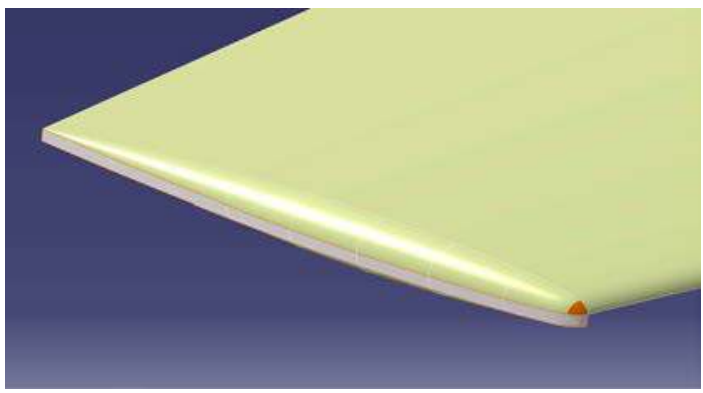

Fig. 16 Closure of wing tip by a fill surface.

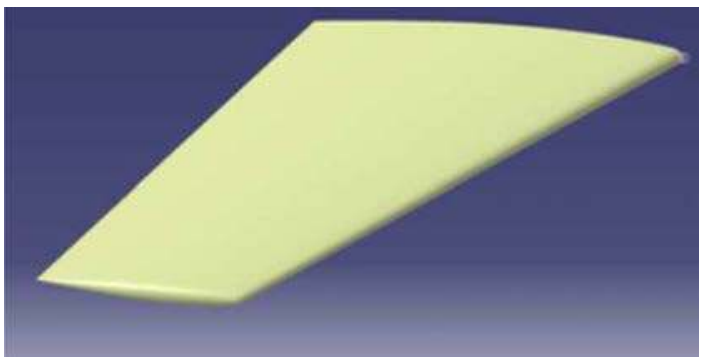

Fig. 17 ONERA-M6 CAD model.

and trailing edge of each profile. This surface was then symmetrized to get the lower-side wing surface. It is worth noting that the process used to build root and tip profiles was also used to build the profile tip curve that belongs to the $x-y$ plane. The only difference is the geometrical constraint imposed at the first point of the profile, which was set tangent to the leading-edge line.

Concerning the tip surface generation, because of the very numerous points defined in the discrete model that appear difficult to handle directly by CATIA, a selection of points was done. From the initial 72 sections, one out of every five sections was selected, starting this extraction from the trailing edge. This process selected only 15 sections with which to work. In each of the selected sections, a new extraction was done, keeping points defined every $10 \mathrm{deg}$. In each section, a B spline passing by all points was defined, with the constraints on each of the extremities (which are passing points defining profile tip) to be tangent to the local sweep of the surface wing. From there, a multisection surface created by lofting was made. A selection of tip curves was used to avoid the ones with end points excluded in the wing tip profile curve generation (section no. 2) or to avoid surface oscillation due to their proximity (section nos. 11, 1315). The guide curves were the wing tip lower-side profile, the tip profile belonging to the $x-y$ plane, and the wing tip upper-side profile. At this point is only left a small surface on the front tip to generate. This surface could be split into two parts: one at the upper side of the wing, and one, symmetric from the $x-y$ plane, at the lower side of the wing. The generation of the surfaces at the upper side of the wing was done by creating a fill surface constrained on tangency on its three boundaries: one made by the tip profile, another made by the extracted tip section no. 12, and the last one made by the tip profile belonging to the $x-y$ plane. Unfortunately, curvature constraints were not possible due to induced oscillations on the surface. To properly set the vertical tangency constraint on this last curve, a surface was created by a downward extrusion of the tip profile curve at $z=0$. The building process of this tip surface is illustrated in Fig. 16 (the grey zone surface). The last operation was to symmetrize this fill surface to get the front tip lower-side surface. The final set of surfaces defining the OM6 test case, will be available in the Initial Graphics Exchange Specification format. A global view of the model is presented in Fig. 17.

\section{B. CFD Mesh}

A structured mesh was generated using ICEM Hexa, Ansys software around the OM6 wing model. A C-H topology presented in Fig. 18 was built. The fine grid is made of 10.2 million nodes. A coarser version of the mesh was also generated. Its size is 3.8 million points. The coarsening process was made inside of ICEM Hexa and ensures a $y+$ on the wall cell close to one.

\section{First Computation}

The two test cases initially retained and named after the AGARD report were test numbers 2308 and 2565. For both, the Mach number considered is 0.84 . The first one is an attached case with an angle of attack of 3.06 deg and a Reynolds number of 11.72 million. The computations of this test for the preceding meshes will be presented here. They are done with the ONERA elsA CFD code [19]. The Jameson scheme with $k i_{2}$ at 0.5 and $k i_{4}$ at 0.016 and the SpalartAllmaras turbulence model were used. A multigrid with one coarse level was used to obtain a convergence of seven orders of the residuals of the first conservative variable and six orders for the turbulent conservative variable on the finest mesh after 20,000 cycles. The coarser version gives a reduction of six orders of magnitude for the first conservative variable and five orders of magnitude reduction in the conservative turbulent variable after 10,000 cycles. Evolution of the residuals is presented in Fig. 19 where $\rho$ is the density and $\rho v$ is the Spalart-Allmaras (SA) variable. In Fig. 20, one can see the lambda created by the coalescence of the two shocks appearing on the top of the wing when looking at the $C_{p}$ contour distribution on the upper surface of the wing.

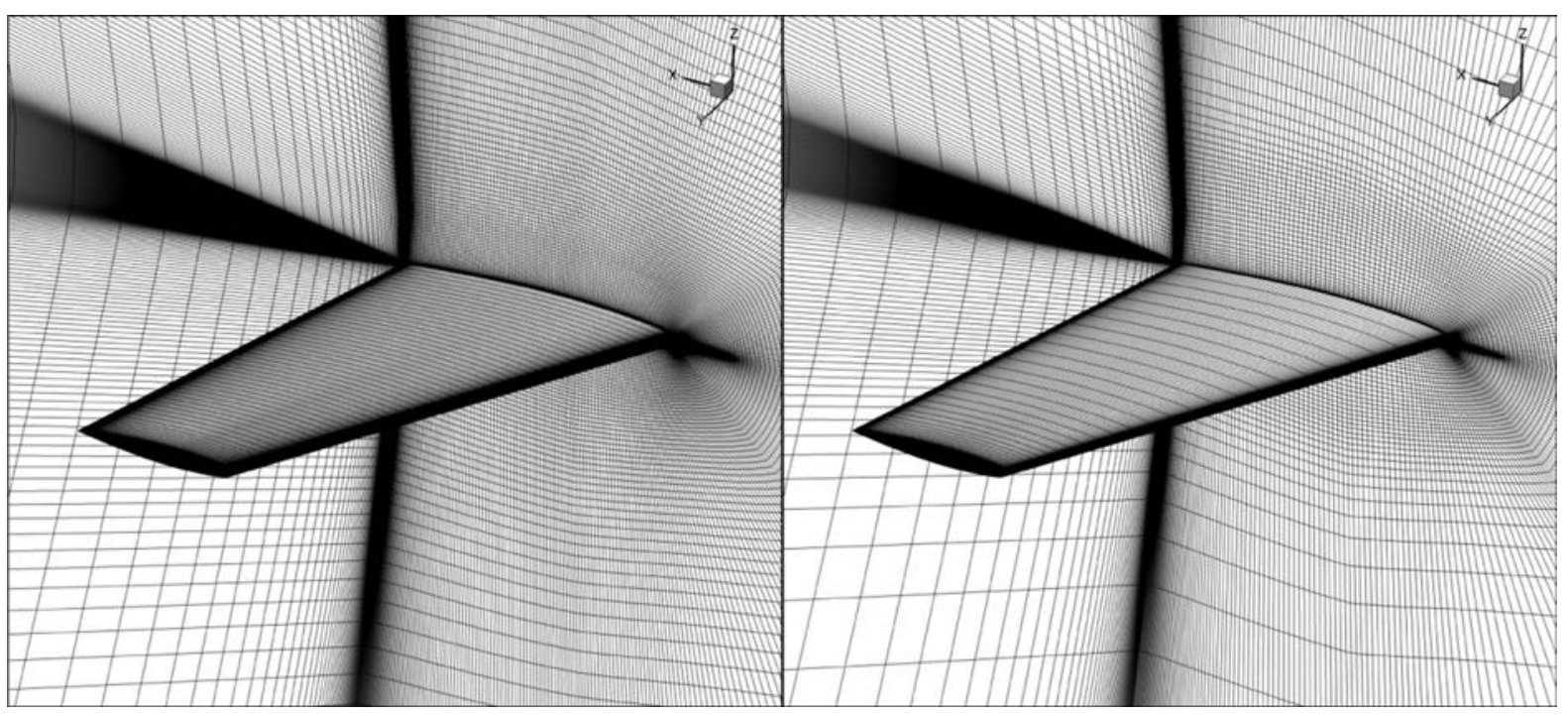

Fig. 18 View of fine (10.2 million) and coarse (3.8 million) C-H meshes over the OM6 wing. 

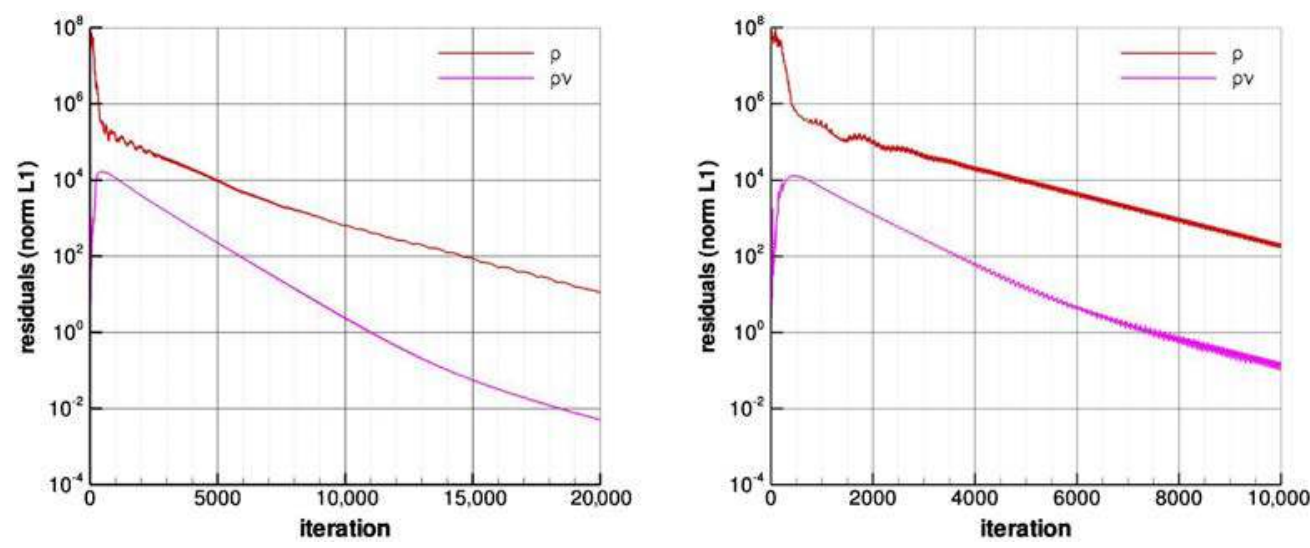

Fig. 19 Residuals history for OM6 attached test case on (left) fine and (right) coarse mesh.

S2MA conditions: $M a c h=0.84, A \circ A=3.06 \mathrm{deg}$

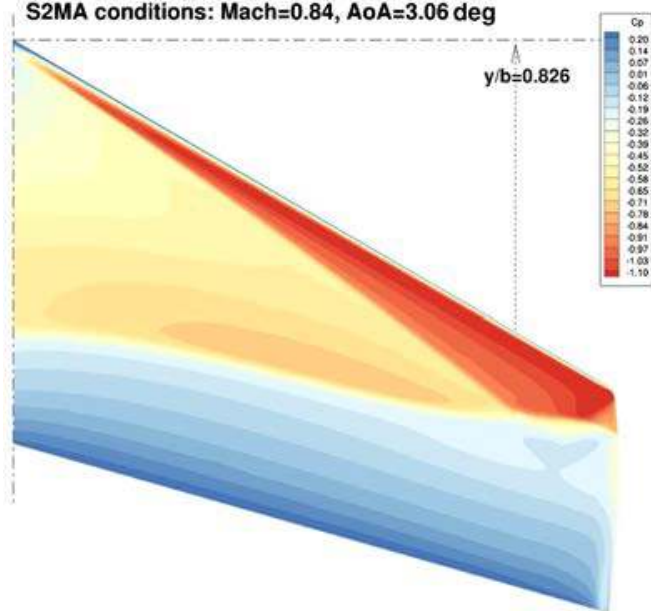

S2MA conditions: $M a c h=0.84, A \circ A=3.06 \mathrm{deg}$

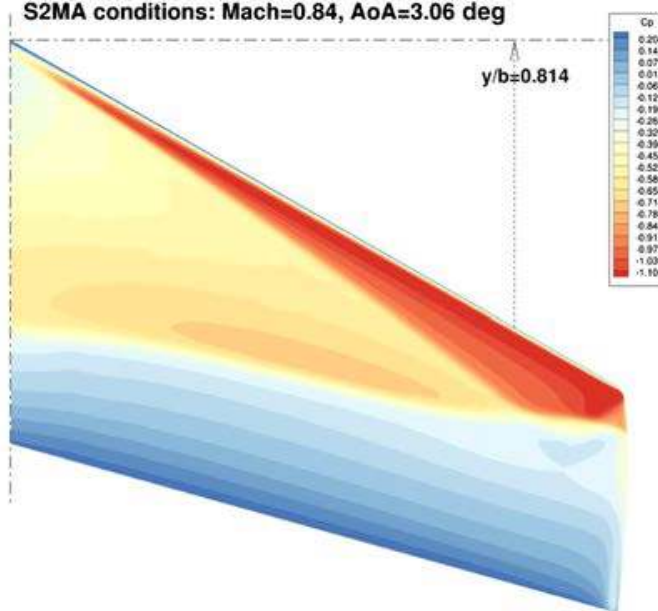

Fig. 20 Upper-side $C_{p}$ distribution for OM6 attached case on (left) fine and (right) coarse mesh.

Section $1(\mathrm{Y} / \mathrm{b})=0.2$

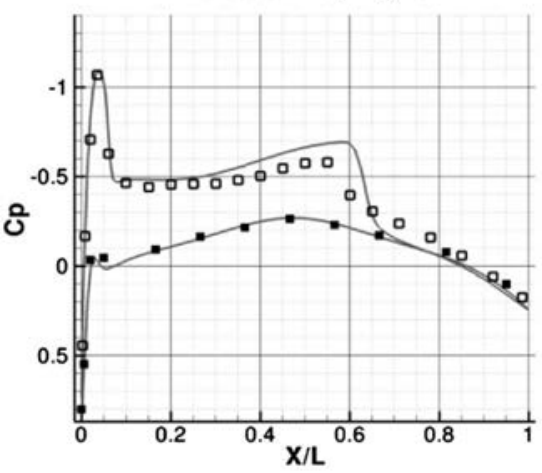

Section $3(Y / b)=0.65$

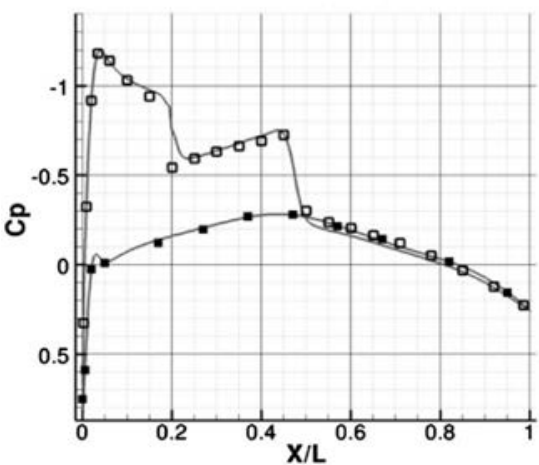

Section $2(\mathrm{Y} / \mathrm{b})=0.44$

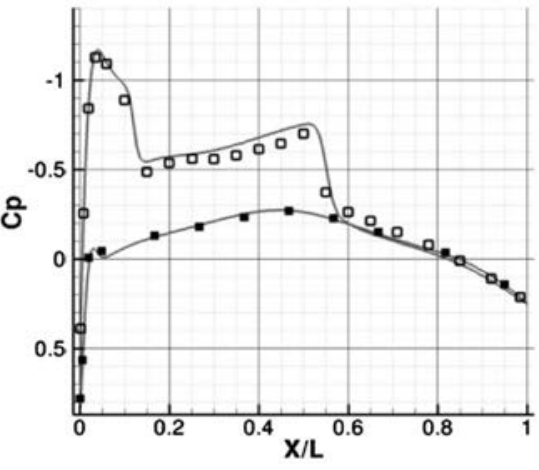

Section $4(Y / b)=0.8$

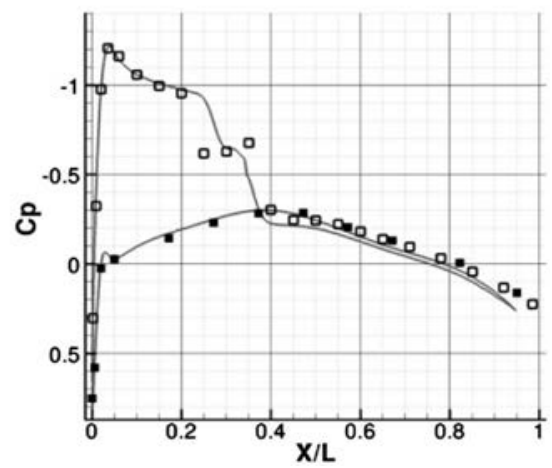

Fig. $21 C_{p}$ comparison (fine mesh) with S2MA experiment for inboard sections (1-4). 
Section $5(Y / b)=0.9$

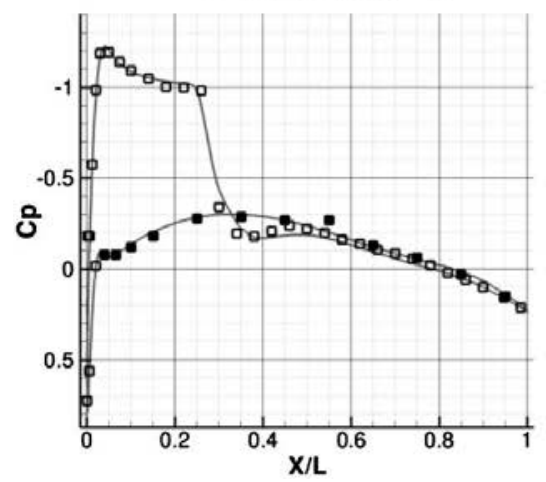

Section $6(Y / b)=0.96$

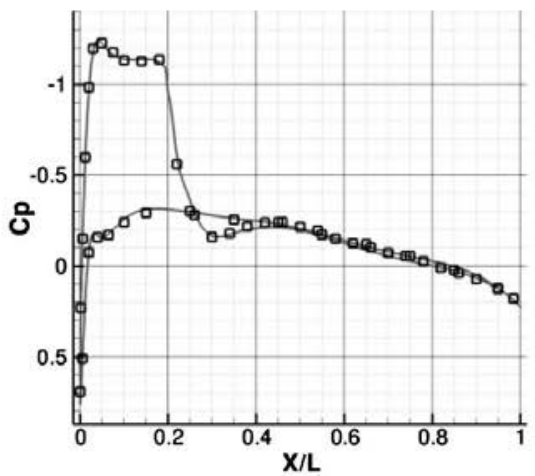

Section $7(\mathrm{Y} / \mathrm{b})=0.99$

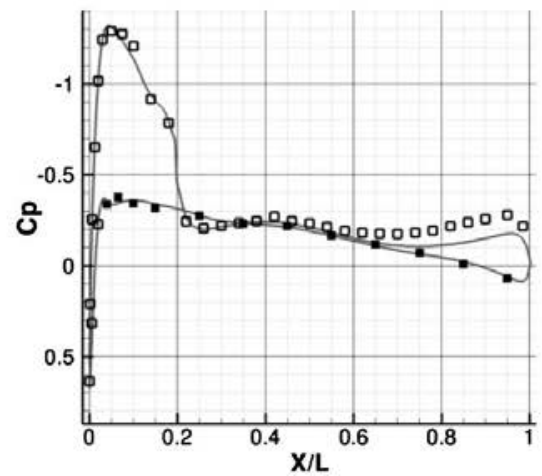

Fig. $22 C_{p}$ comparison (fine mesh) with S2MA experiment for wing tip sections (5-7).

Section $1(Y / b)=0.2$

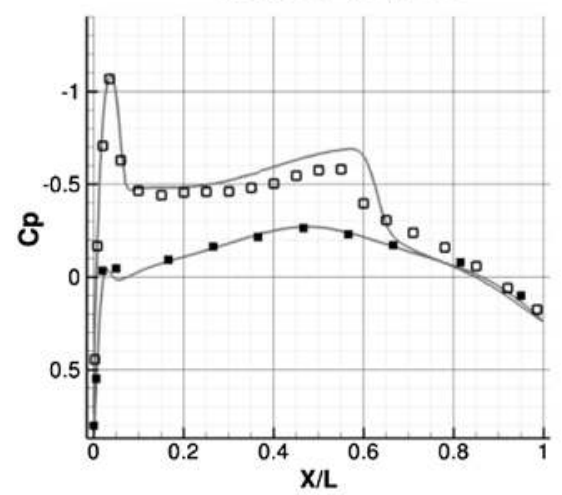

Section $3(\mathrm{Y} / \mathrm{b})=0.65$

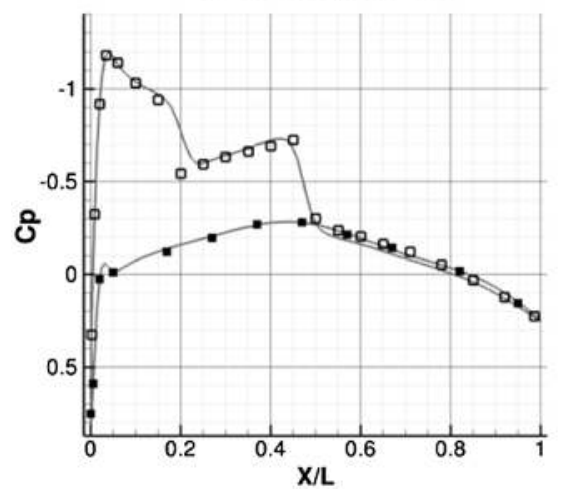

Section $2(\mathrm{Y} / \mathrm{b})=0.44$

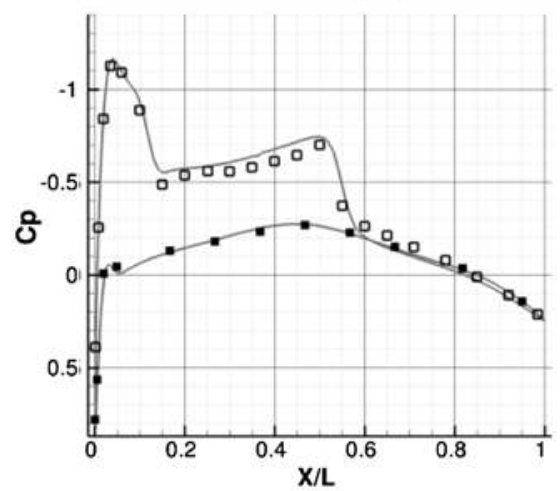

Section $4(Y / b)=0.8$

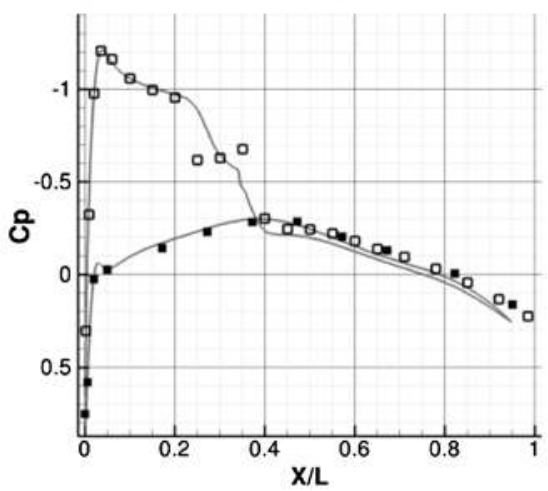

Fig. $23 C_{p}$ comparison (coarse mesh) with S2MA experiment for inboard sections (1-4).

Section $5(Y / b)=0.9$

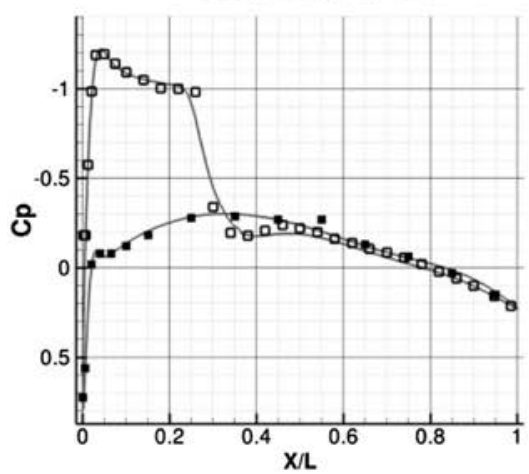

Section $6(Y / b)=0.96$

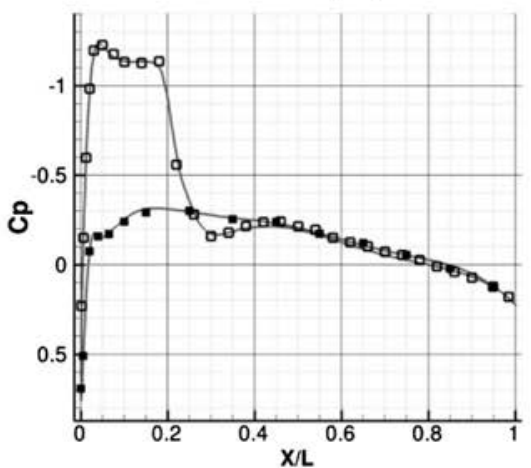

Section $7(Y / b)=0.99$

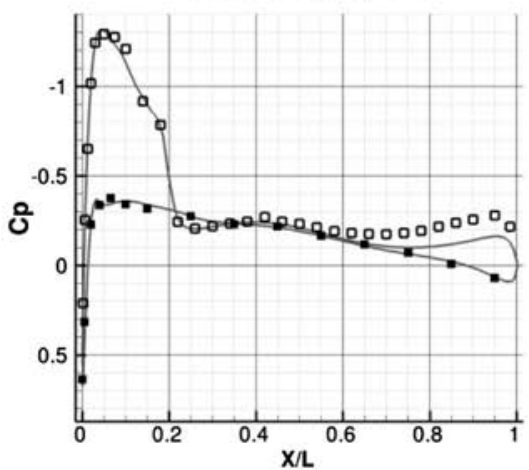

Fig. $24 C_{p}$ comparison (coarse mesh) with S2MA experiment for wing tip sections (5-7).

13 


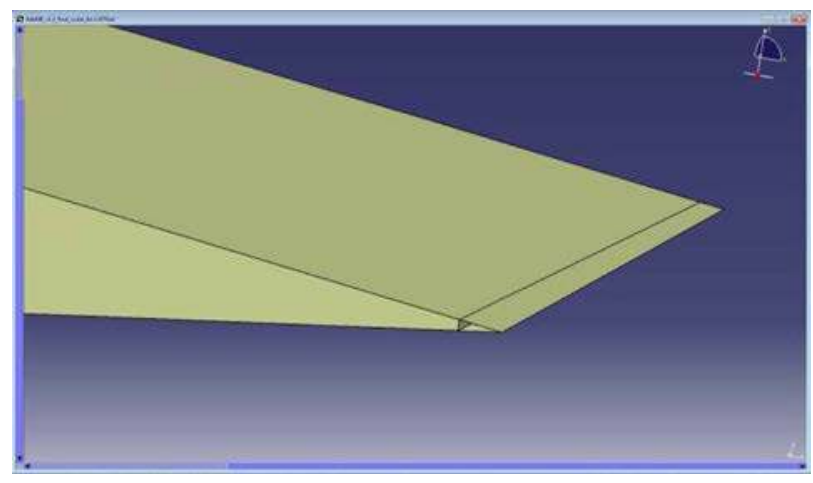

Fig. 25 ONERA-M6 sharp trailing-edge CAD building.

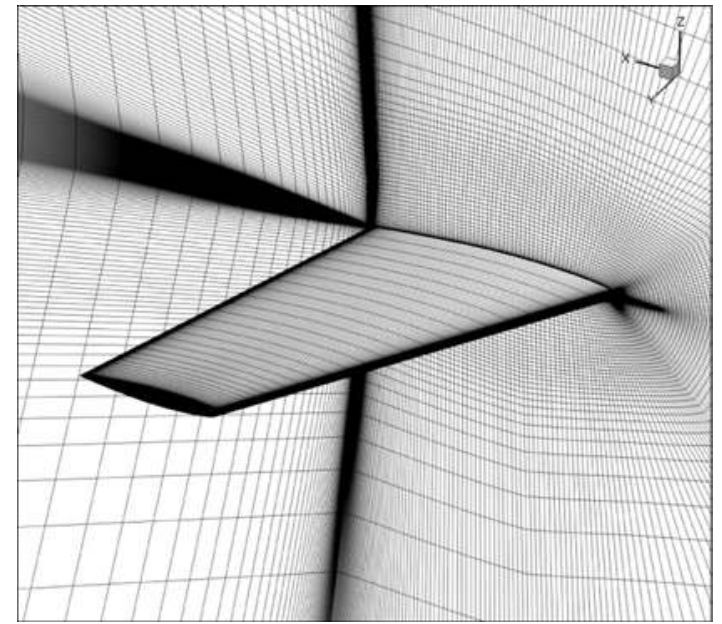

Fig. 26 View of C-H meshes over the OM6 wing with sharp trailing edge.

When looking at the $C_{p}$ contour distribution on the upper surface of the wing, both meshes well capture the lambda created by the coalescence of the two shocks appearing on the top of the wing. Results are different when looking at the exact point where the two shocks meet; this point appears to be at $y / b=0.826$ for the finest mesh and at $y / b=0.814$ for the coarse mesh.

In Figs. 21 and 22, computation on the fine mesh is compared with the experiment. In section 1, elsA find a stronger shock than in the experiment, and at section 4, elsA predicts the meeting of the two

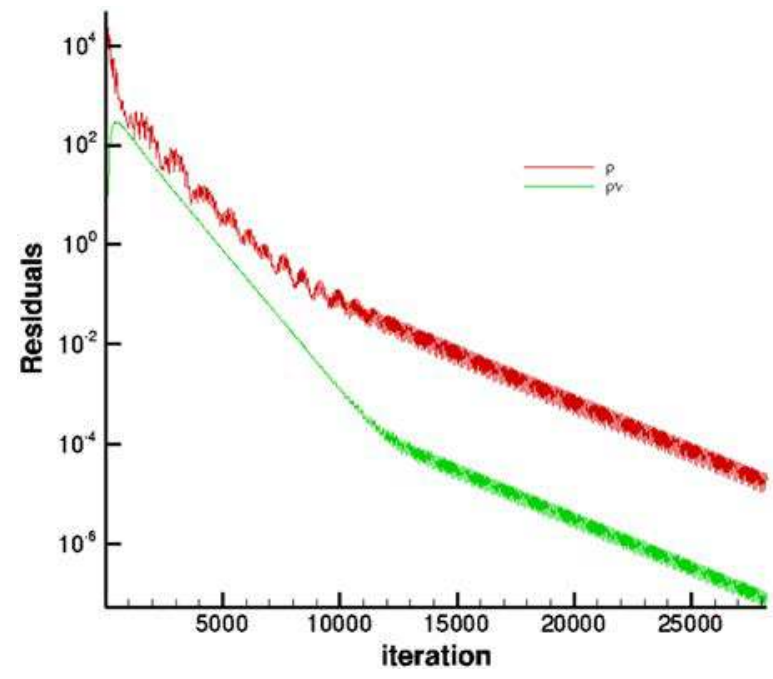

shocks at a different spanwise station than in the experiment. One can recall that the ideal symmetry condition used in the computation does not exactly reproduce the flow physics of the half-wing with boundary-layer diverter placed in the wind tunnel during the experiment. The computation done on the coarser mesh (Figs. 23 and 24) shows the same kind of discrepancies already seen in the finer computation at sections 1 and 4 . In others sections, elsA predicts precisely the pressure coefficients. It might be interesting to model the pressure diverter in future work.

\section{ONERA-M6 Wing CAD Model with Sharp Trailing Edge}

Taking into account the NASA TMR technical discussion group participants' suggestion, that a sharp trailing edge would make the test case easier to run, a modification of the preview OM6 CAD model is presented, as well as the mesh and computations for the attached test 2308 case. Effects of the turbulence model are considered by using the SA and $k-\omega$ Menter SST models.

A sharp trailing edge has been added to the initial CAD model. This was made by prolongation of all surfaces joining the wing base, as can be seen in Fig. 25. The wing chordwise extension is $0.55 \%$ of local chord. The trailing edge created is a straight line.

\section{E. CFD Mesh of the ONERA-M6 Wing with Sharp Trailing Edge}

A structured mesh was generated using ICEM Hexa, Ansys software around the CAD of the OM6 wing with sharp trailing edge. The C-H topology presented in Fig. 26 was built. A grid of 3.8 million points has been generated for the demonstration.

\section{F. Computation of the Attached Case S2MA (2308)}

In this section, we investigate effects of turbulence models (SA and $k-\omega$ Menter SST) with the proposed mesh with a sharp trailing edge. The Jameson scheme with $k i_{2}$ at 0.5 and $k i_{4}$ at 0.016 was used. A multigrid with one coarse level was used to obtain a convergence of seven orders of the residuals of the first conservative variable and six orders for the turbulent variable after 30,000 cycles. Evolution of the residuals is presented in Fig. 27 where $\rho$ is the density and $\rho v$ is the Spalart-Allmaras (SA) variable.

In Fig. 28, when looking at the $C_{p}$ contour distribution on the upper surface of the wing, both models well capture the lambda created by the coalescence of the two shocks appearing on the top of the wing. The exact point where the two shocks meet appears to be at $y / b=0.814$.

In Figs. 29 and 30, for aerodynamic aspects, conclusions are exactly the same as those in Sec. V.C. For the modeling aspect, Boussinesq models Spalart-Allmaras and $k-\omega$ Menter SST give the same results.

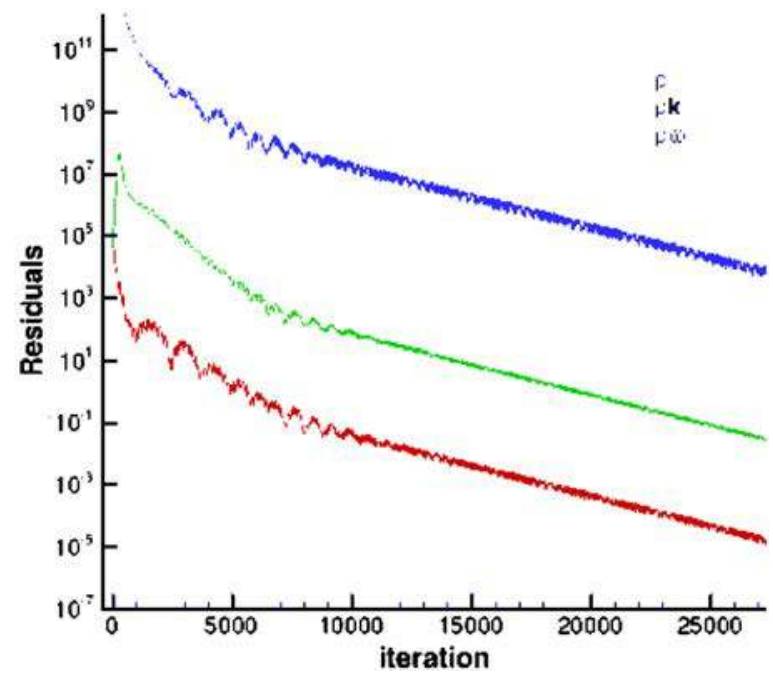

Fig. 27 Residual history for OM6 attached test case: (left) SA model and (right) $k$ - $\omega$ Menter SST . 

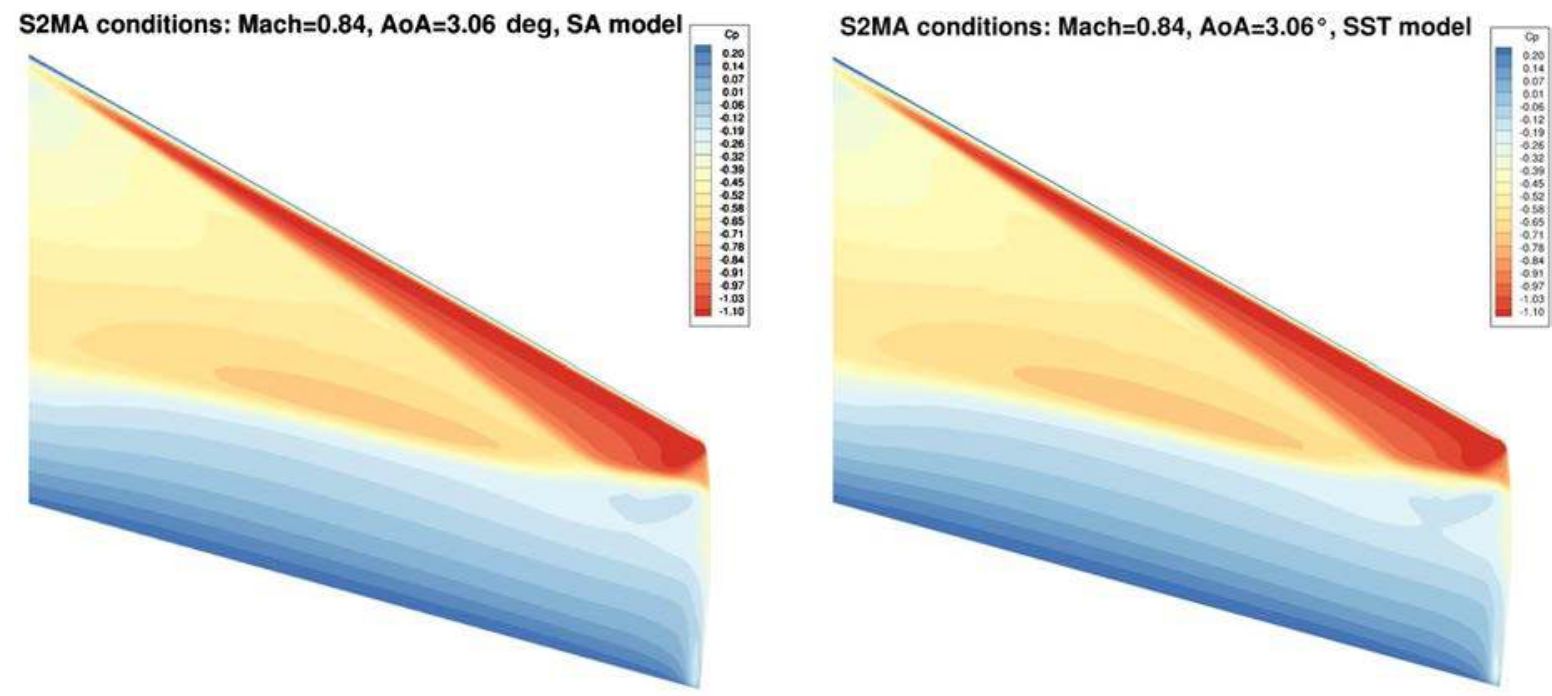

Fig. 28 Upper-side $C_{p}$ distribution for OM6 attached case: (left) SA model and (right) $k$ - $\omega$ Menter SST.

Section $1(\mathrm{Y} / \mathrm{b})=0.2$

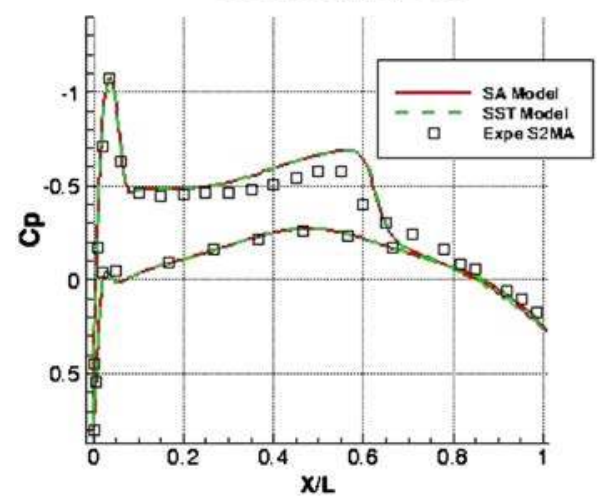

Section $3(\mathrm{Y} / \mathrm{b})=0.65$

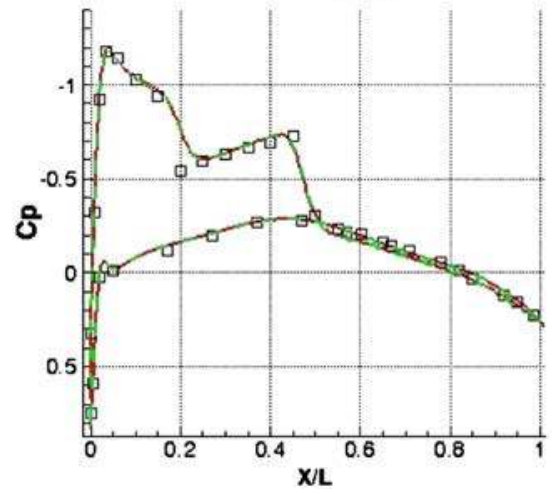

Section $2(\mathrm{Y} / \mathrm{b})=0.44$

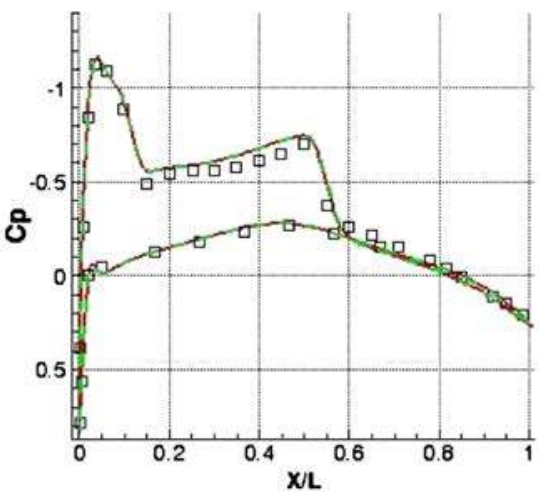

Section $4(\mathrm{Y} / \mathrm{b})=0.8$

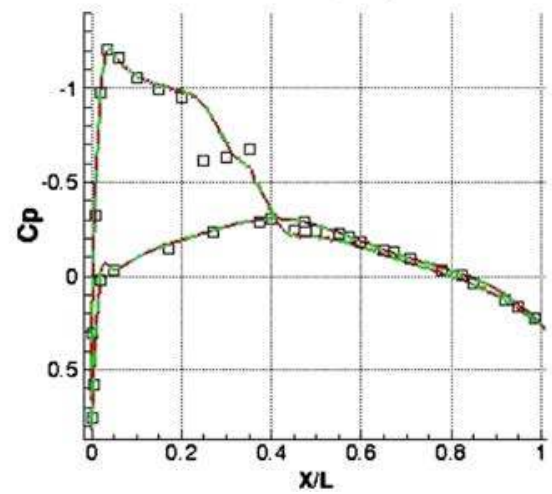

Fig. $29 C_{p}$ comparison with S2MA experiment for inboard sections (1-4).

Sectlon $5(Y / b)=0.9$

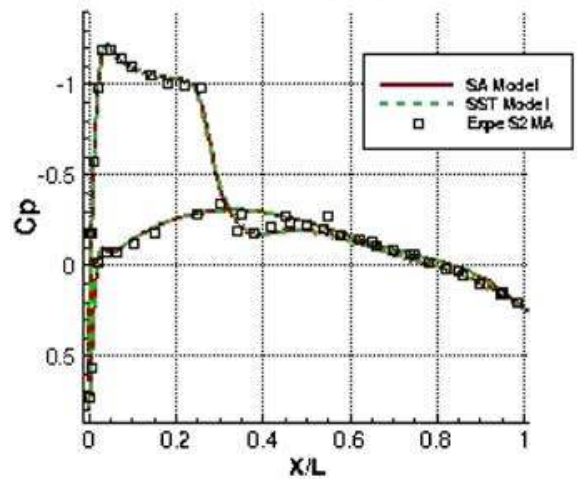

Sectlon $6(Y / b)=0.96$

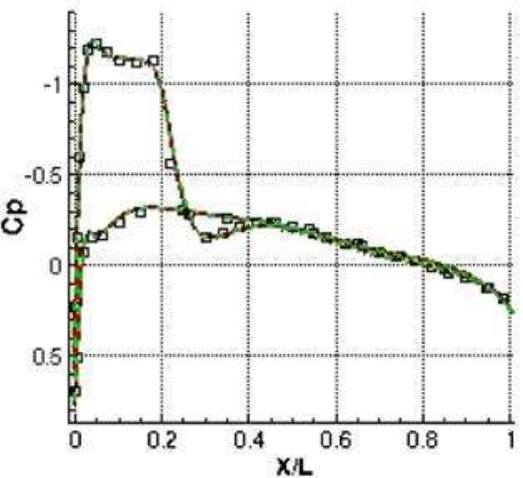

Sectlon $7(\mathrm{Y} / \mathrm{b})=0.99$

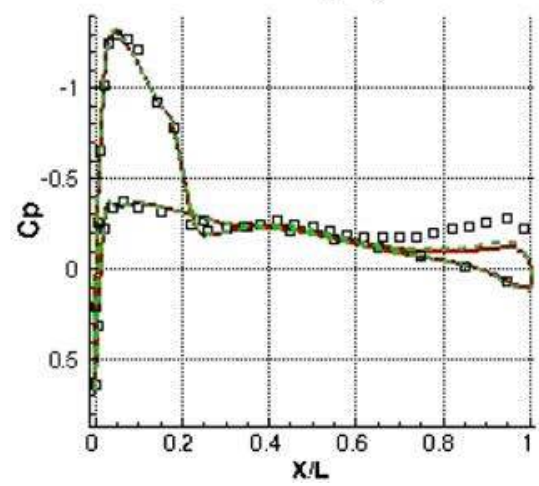

Fig. $30 C_{p}$ comparison with S2MA experiment for wing tip sections (5-7). 


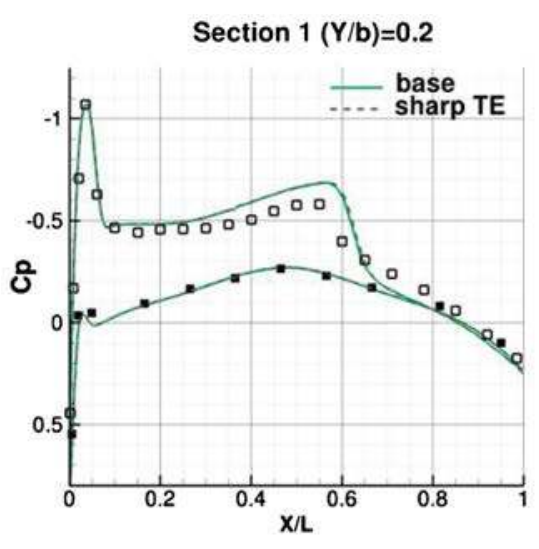

Section $3(\mathrm{Y} / \mathrm{b})=0.65$

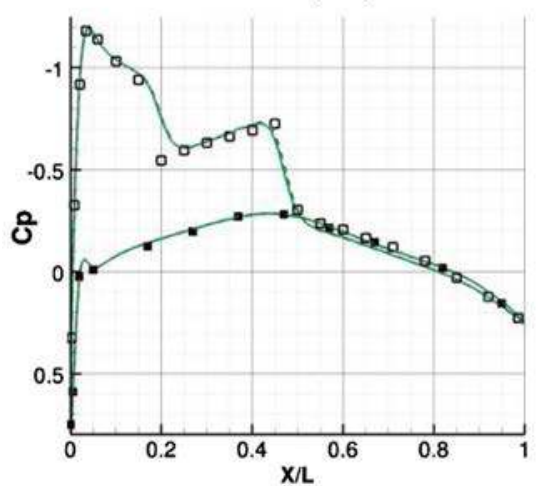

Section $2(Y / b)=0.44$

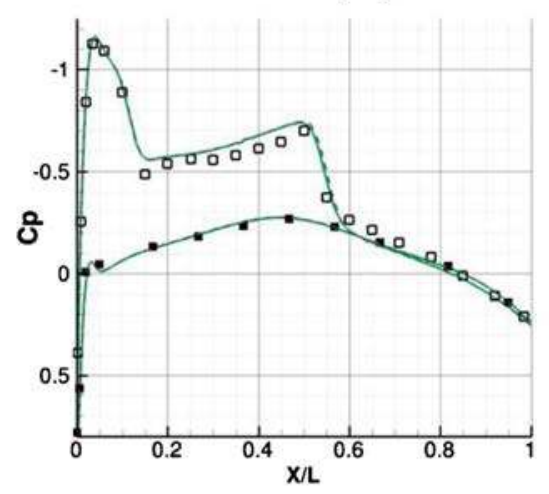

Section $4(Y / b)=0.8$

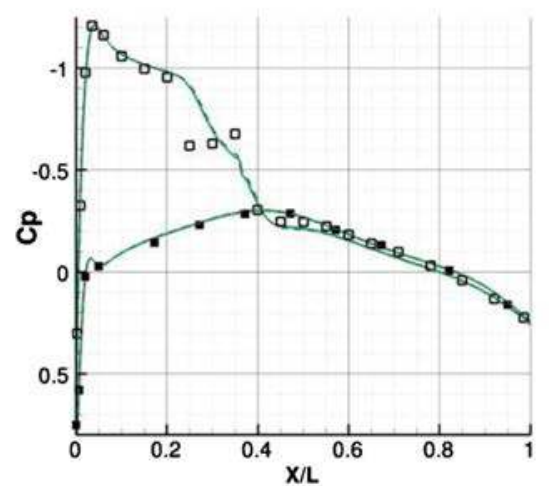

Fig. $31 C_{p}$ comparison of computations on coarse mesh (without and with sharp TE) with S2MA experiment for inboard sections (1-4): SA model.
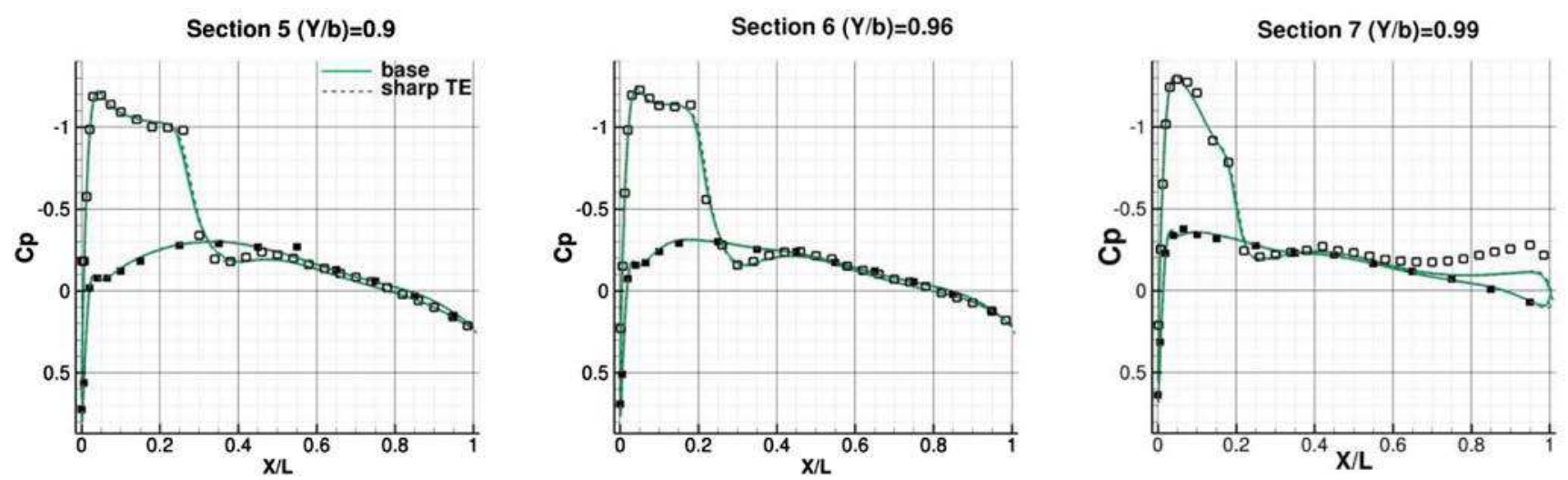

Fig. $32 C_{p}$ comparison of computations on coarse mesh (without and with sharp TE) with S2MA experiment for wing tip sections (5-7): SA model.

\section{G. Sharp Trailing-Edge Effect}

It could be interesting to have an idea of the influence of the modelization of the trailing edge (TE). Figures 31 and 32 show a comparison of two computations: one called "base" done on the coarse mesh detailed in Sec. V.B, and the other called "sharp TE" done on the mesh from the new CAD with a sharp trailing edge and detailed in Sec. V.E. The sharp trailing edge has a very small influence on $C_{p}$ behavior.

\section{Conclusions}

The NACA0012 configuration has been computed on different grids proposed on the TMR site. Results between elsA and CFL3D are reasonably close. The trailing-edge streamwise discretization has an influence on the results, particularly on lift, pitching moment, and the viscous part on the drag; it should be interesting to perform the same computations with a point vortex correction, which will limit the influence of the far-field boundary condition. This option is already proposed on the TMR site. For subsonic computation with elsA, the AUSM+(P) scheme [4] is systematically used because of its robustness and the good artificial dissipation scaling for low Mach number flows. Nevertheless, a wavy solution very near the trailing edge seems to make the convergence very slow; tests on the spatial scheme will be performed.

For the OM6 wing test case, a discrete geometry representation based on the AGARD report was introduced and a summary of the experimental test in the S2MA ONERA wind tunnel was done. From then, the CAD model generation as well as two computational meshes sharing the same topology, but different in the number of points, were presented for real geometry with a blunt trailing edge. The results obtained with the Jameson scheme and the SpalartAllmaras turbulence model, for the attached test case 2308 (Mach number of 0.84 and angle of attack of $3.06 \mathrm{deg}$ ), were compared with the experiment and showed good agreement. A CAD model has also been generated with a sharp trailing edge to avoid the convergence problem. Computation results have shown that the sharp trailing edge has a negligible effect on the pressure coefficient. A family of structured and unstructured meshes based on this new CAD model with a sharp trailing edge will be generated in 2016 for turbulence modeling resources and the CFD community. 


\section{References}

[1] Cambier, L., Gleize, V., and Mayeur, J., "Verification and Validation of the ONERA elsA Flow Solver on RANS Benchmarks," AIAA SciTech 2014, AIAA Paper 2014-239, Jan. 2014.

[2] Cambier, L., and Gazaix, M., "elsA: An Efficient Object-Oriented Solution to CFD Complexity," 40th AIAA Aerospace Science Meeting and Exhibit, AIAA Paper 2002-0108, Jan. 2002.

[3] Rumsey, C. L., Smith, B. R., and Huang, G. P., "Description of a Website Resource for Turbulence Modeling Verification and Validation," 40th AIAA Fluid Dynamics Conference and Exhibit, AIAA Paper 20104742, June 2010.

[4] Mary, I., and Sagaut, P., "Large Eddy Simulation of Flow Around an Airfoil Near Stall," AIAA Journal, Vol. 40, No. 6, 2002, pp. 1139-1145. doi: $10.2514 / 2.1763$

[5] Liou, M.-S., and Steffen, C. J., Jr., "A New Flux Splitting Scheme," Journal of Computational Physics, Vol. 107, No. 1, 1993, pp. 23-39. doi:10.1006/jcph.1993.1122

[6] Gregory, N., and O'Reilly, C. L., "Low-Speed Aerodynamic Characteristics of NACA 0012 Aerofoil Sections, Including the Effects of Upper-Surface Roughness Simulation Hoar Frost," NASA R\&M3726, Jan. 1970.

[7] Ladson, C. L., "Effects of Independent Variation of Mach and Reynolds Numbers on the Low-Speed Aerodynamic Characteristics of the NACA 0012 Airfoil Section," NASA TM-4074, Oct. 1988.

[8] Jameson, A., and Caughey, D. A., "Numerical Calculation of the Transonic Flow past a Swept Wing," Mathematics and Computing, New York Univ., Energy Research and Development Authority Rept., New York, June 1977.

[9] Jameson, A., and Caughey, D. A., "Recent Progress in Finite-Volume Calculations for Wing-Fuselage Combinations," AIAA 12th Fluid and Plasma Dynamics Conference, AIAA Paper 1979-1513, July 1979.

[10] Jameson, A., "Transonic Airfoil Calculations Using the Euler Equations," Proceedings of IMA Conference on Numerical Methods in Aeronautical Fluid Dynamics, edited by Roe, P. L., Academic Press, New York, 1982, pp. 289-308.

[11] Monnerie, B., and Charpin, F., "Essais de Buffeting d'une Aile en Flèche en Transsonique," 10th Symposium of Applied Aerodynamics, Fluid
Mechanics Institute, Nov. 1973; also Aeronautics and Astronautics Journal, Vol. 50, No. 1, 1975, pp. 3-16.

[12] Vatsa, V. N., "Accurate Numerical Solutions for Transonic Viscous Flow over Finite Wings," Journal of Aircraft, Vol. 24, No. 6, June 1987, pp. $377-385$. doi: $10.2514 / 3.45456$

[13] Abid, R., Vatsa, V. N., Johnson, D. A., and Wedan, B. W., "Prediction of Separated Transonic Wing Flows with a Non-Equilibrium Algebraic Model," AIAA 27th Aerospace Sciences Meeting, AIAA Paper 19890558, Jan. 1989.

[14] Radespiel, R., Rossow, C., and Swanson, R. C., "An Efficient CellVertex Multigrid Scheme for the Three-Dimensional Navier-Stokes Equations," AIAA Ninth Computational Fluid Dynamics Conference, AIAA Paper 1989-1953, June 1989.

[15] Rumsey, C. L., and Vatsa, V. N., "Comparison of the Predictive Capabilities of Several Turbulence Models Viscous Flow over Finite Wings," Journal of Aircraft, Vol. 32, No. 3, May-June 1995, pp. 510-514. doi: $10.2514 / 3.46749$

[16] May, G., and Jameson, A., "Unstructured Algorithms for Inviscid and Viscous Flows Embedded in a Unified Solver Architecture: Flo3xx," 43rd Aerospace Sciences Meeting and Exhibit, AIAA Paper 20050318, Jan. 2005.

[17] Schmitt, V., and Charpin, F., "Pressure Distributions on the ONERAM6-Wing at Transonic Mach Numbers," Experimental Data Base for Computer Program Assessment, AGARD Advisory Rept. AR-138, May 1979.

[18] Vassberg, J. C., Dehann, M. A., Rivers, S. M., and Wahls, R. A., "Development of a Common Research Model for Applied CFD Validation Studies," 26th AIAA Applied Aerodynamics Conference, AIAA Paper 2008-6919, Aug. 2008.

[19] Cambier, L., Heib, S., and Plot, S., "The ONERA elsA CFD Software: Input from Research and Feedback from Industry," Mechanics \& Industry, Vol. 14, No. 3, 2013, pp. 159-174. doi: $10.1051 / \mathrm{meca} / 2013056$ 